\title{
Prediction of Geometrical Characteristics and Process Parameter Optimization of Laser Deposition AISI 316 Steel Using Fuzzy Inference
}

Daniel René Tasé Velázquez ( $\nabla$ dtasev88@gmail.com )

Methodist University of Piracicaba https://orcid.org/0000-0002-3161-5898

André Luís Helleno

Mackenzie Presbyterian University

Hipólito Carvajal Fals

Oriente University

Raphael Galdino dos Santos

Institute for Education and Research, São Paulo, Brazil.

\section{Research Article}

Keywords: Laser Metal Deposition, Fuzzy Inference, Bead geometry prediction, Deposition Process Parameters, AISI 316 stainless steel

Posted Date: March 17th, 2021

DOI: https://doi.org/10.21203/rs.3.rs-296663/v1

License: (9) This work is licensed under a Creative Commons Attribution 4.0 International License. Read Full License 


\title{
Prediction of geometrical characteristics and process parameter optimization of laser deposition AISI 316 steel using fuzzy inference
}

\author{
Daniel René Tasé Velázquez ${ }^{1 *}$, André Luís Helleno², Hipólito Carvajal Fals ${ }^{3,4}$, Raphael Galdino dos \\ Santos $^{5}$ \\ ${ }^{1}$ Production Engineering Post-Graduation Program, Methodist University of Piracicaba, São Paulo, Brazil. \\ ${ }^{2}$ Engineering School, Mackenzie Presbyterian University, São Paulo, Brazil. \\ ${ }^{3}$ College of Mechanical and Industrial Engineering, Oriente University, Santiago de Cuba, Cuba. \\ ${ }^{4}$ Visiting Professor at Federal Technological University of Paraná, Paraná, Brazil. \\ ${ }^{5}$ Insper - Institute for Education and Research, São Paulo, Brazil. \\ *Corresponding author: dtasev88@gmail.com
}

\begin{abstract}
Laser Metal Deposition (LMD) process is an additive manufacturing technique that has attracted the interest of the automotive and aerospace industries due to its ability to manufacture parts with complex geometries and different types of metallic materials. However, the structure of the deposited layers and the geometrical characteristics of the manufactured parts are influenced by the interaction among the deposition process parameters. In this paper, fuzzy inference (FIS) technique was used to develop two models for predicting the geometrical characteristics and, for optimizing the LMD process parameters using AISI 316 stainless steel powder and substrate. An experimental design, based on factorial analysis, was used to correlate the influence of selected deposition process parameters, laser power (Lp), powder flow (Pf) and focal length $(\mathrm{Fl})$ with the process geometrical characteristics bead height $(\mathrm{Bh})$, bead width $(\mathrm{Bw})$, depth of penetration $(\mathrm{Dp})$, dilution $(\mathrm{d})$ and wetting angle (wa). The factors $\mathrm{Lp}$ and $\mathrm{Fl}$ were used with three operating levels each: $\mathrm{Lp}=225 \mathrm{~W}, 250 \mathrm{~W}, 275 \mathrm{~W}$, and $\mathrm{Fl}=4.8 \mathrm{~mm}, 5.0$ $\mathrm{mm}, 5.2 \mathrm{~mm}$. The factor Pf was used with two levels, $9.40 \mathrm{~g} / \mathrm{s}$ and $13.35 \mathrm{~g} / \mathrm{s}$. Analysis of variance allowed identifying that the Pf affect the $B h$, $B h / B w$ ratio, $d$ and $w a$. The increase in Laser power (Lp) resulted in an increase of the geometric characteristics Bw and Dp. The first FIS, for predicting the bead's geometrical characteristics, presented high adequacy (relative error up to $8.43 \%$ ) for assessing the experimental conditions. The second FIS indicated the best possible interaction, given the studied operating conditions and the variables evaluated. The maximum Output Defuzzified Index $(\mathrm{ODI}=0.845)$ was obtained with the deposition process parameters $\mathrm{Lp}=250 \mathrm{~W}, \mathrm{Fl}=5 \mathrm{~mm}$, and $\mathrm{Pf}=$ $9.40 \mathrm{~g} / \mathrm{s}$.
\end{abstract}

Keywords: Laser Metal Deposition, Fuzzy Inference, Bead geometry prediction, Deposition Process Parameters, AISI 316 stainless steel

\section{Introduction}

Hybrid manufacturing technologies (HMT) have attracted increasing attention from industry and academia [1]. Newman et al. [2] declare that the suitability of the HMT for combining processes/machines with flexibility and agility in changing manufacturing processes has allowed better utilization of resources, materials and reduce the time-to-market of complex parts and components normally used in the automotive and aerospace industries.

Flynn et al. [3] showed that two additive processes have been predominantly adopted by the industrial sector for metallic 3D fabrication: Laser Powder Bed Fusion (L-PBF) and Laser Metal Deposition (LMD). Cortina et al. [4] affirmed that Selective Laser Melting (SLM) is a common technique related to L-PBF process. This technique is based on the pre-deposited powder selective melting by a thermal source that usually is a laser beam that generates a thin layer of melted material, and for guaranteeing the unvarying powder distribution, a levelling system (roller or re-coater blade) is used.

Herzog et al. [5] asserted that this is a cyclic process until the 3D part is built. An advantage of this technique is the reuse of non-melted material. This is possible because L-PBF process is performed on a build platform inside an enclosed build chamber filled with inert gas. Liverani et al. [6] studied the effect of SLM process parameters on microstructure, defect formation and mechanical properties of 316L austenitic stainless steel. The results identified the correlation between the process parameters, microstructure, and mechanical properties of the analyzed samples. Defects in the deposition process as gas pores, voids and binging appeared with $150 \mathrm{~W}$ of laser power. Thus, a study using higher laser powers could allow analyzing the correlation between high energy density and the deposition defects evaluated.

Shipley et al. [7] studied the process parameters optimization to address the challenges of martensitic microstructures, porosity, and residual stresses during addition of Ti-6Al-4V. In this study, concerning process optimization, the part density maximization was the primary studied goal due to the negative effect of pores on fracture and fatigue properties. Gu et al. [8] studied the powder flow behavior on fluid thermodynamics and laser processability of Ni-based composites. They conclude that the powder-particle size had significant effect on the surface quality. Larger powder particles caused porosity on the part surface. However, they only studied the powder-particles behavior on two deposited layers and highlighted that future studies could be focused on applying the physical model to analyze the interaction of laser power and particle sizes and their effects on multideposited layers. Murkute et al. [9] studied 316L stainless steel clads corrosion-resistant deposited on carbon steel substrate using L-PBF-SLM process. They found that a higher energy density was necessary to produce low-defect dense clads with good adherence to the substrate. The porosity measurement and the relationship between projected layer height and penetration versus the ones achieved were not considered in the analysis. 
The studies discussed above reveal interesting applications of L-PBF additive process and future directions to be explored. However, Cortina et al. [4] alleged that the main application of L-PBF processes has been the fabrication of full-3D parts with high-complexity shapes. Morgan et al. [10] sustained that two principal constraints associated to L-PBF process are the build rate and the size of the build chamber that limits the part size.

Flynn et al. [3] affirmed that the most common process integrated to a hybrid system is the Laser Metal Deposition (LMD) technique, linked to Directed Energy Deposition (DED) process, which is faster than L-PBF process. LMD is also known as Laser Engineered Net Shaping (LENS), Direct Metal Deposition (DMD), Laser Cladding (LC) or Direct Laser Deposition (DLD) [11].

In the LMD process, as explained by Schmidt et al. [12], the metallic powder is carried through a feed nozzle whereby a flow of inert gas (helium or argon) creates a protective area for depositing material. The powder is completely fused by a highpower laser beam in a layer-by-layer pattern to create 3D parts. Cortina et al. [4] indicated that LMD process has been advantageous due to its versatility for remanufacturing, building, and repairing complex geometries and high value-added parts. Other highlights have been the small heat zone generated during the deposition process and the higher deposition rate when compared to other additive processes such as SLM. They also suggest, regardless of the application field of this additive process, there is an appealed necessity to develop predictive models to analyze the process parameters performance (depositing conditions) and response-variables (geometrical characteristics) to evaluate, reduce and eliminate the deposition defects.

Several studies can be found in the literature exploring the development of mostly statistical models for simulating and predicting LMD process parameters behavior assessing different response-variables. Table 1 summarizes the key features of some of those studies, which are discussed next, including materials, experimental approach, key process parameters and output variables assessed.

Table 1. Summary of the literature review on LMD process

\begin{tabular}{|c|c|c|c|c|}
\hline Author & Materials & $\begin{array}{l}\text { Experimental } \\
\text { approach }\end{array}$ & Process parameters & Outputs assessed \\
\hline Lee [13] & $\begin{array}{l}\text { Powder: Co alloy } \\
\text { Substrate: AISI } 4135\end{array}$ & Taguchi method & $\begin{array}{l}\text { Shielding gas type, laser pulse } \\
\text { shape, powder feed rate, travel } \\
\text { speed, powder feed angle, } \\
\text { powder feed position, focal } \\
\text { position }\end{array}$ & Deposition process efficiency \\
\hline Sun and Hao [14] & $\begin{array}{l}\text { Powder: Ti6Al4V } \\
\text { Substrate: Ti6Al4V }\end{array}$ & $\begin{array}{l}\text { CCD-RSM- } \\
\text { ANOVA }\end{array}$ & $\begin{array}{l}\text { Laser power, scanning speed, } \\
\text { powder feed rate }\end{array}$ & Bead geometry \\
\hline Graf et al. [15] & $\begin{array}{l}\text { Ni-based superalloy } \\
\text { René } 80\end{array}$ & Full factorial design & $\begin{array}{l}\text { Laser power, laser spot } \\
\text { diameter, welding velocity, } \\
\text { powder mass flow }\end{array}$ & Bead geometry \\
\hline $\begin{array}{l}\text { Farahmand \& } \\
\text { Kovacevic [16] }\end{array}$ & $\begin{array}{l}\text { Powder: AISI H13 } \\
\text { Substrate: ASTM A36 }\end{array}$ & $\begin{array}{l}\text { CCD-RSM- } \\
\text { ANOVA }\end{array}$ & $\begin{array}{l}\text { Laser power, scanning speed, } \\
\text { powder feed rate }\end{array}$ & $\begin{array}{l}\text { Bead geometry and } \\
\text { microhardness }\end{array}$ \\
\hline Liu \& Kovacevic & Powder: Fe-based alloy & CCD-RSM- & Laser power, powder feeding & Powder catchment efficiency \\
\hline$[17]$ & Substrate: ASTM A36 & ANOVA & $\begin{array}{l}\text { rate, carrier-gas flow rate, } \\
\text { stand-off distance }\end{array}$ & $\begin{array}{l}\text { and behavior, } \\
\text { clad geometry }\end{array}$ \\
\hline Yu et al. [18] & $\begin{array}{l}\text { Powder: YCF101 steel } \\
\text { Substrate: } 45 \text { steel }\end{array}$ & $\begin{array}{l}\text { Orthogonal array- } \\
\text { ANOVA }\end{array}$ & $\begin{array}{l}\text { Laser power, scan velocity, } \\
\text { powder feed rate, laser spot } \\
\text { diameter }\end{array}$ & $\begin{array}{l}\text { Bead geometry, mechanical } \\
\text { properties and microstructure }\end{array}$ \\
\hline Wu et al. [19] & Powder: 316L SS & Numerical modeling & Laser beam, powder stream & $\begin{array}{l}\text { Laser attenuation, heat } \\
\text { transport }\end{array}$ \\
\hline Huang et al. [20] & $\begin{array}{l}\text { Powder: } 316 \mathrm{~L} \mathrm{SS} \text {, } \\
\text { Inconel } 625\end{array}$ & Numerical modeling & $\begin{array}{l}\text { Laser power, scanning speed, } \\
\text { powder feed rate, laser beam } \\
\text { diameter and others. }\end{array}$ & $\begin{array}{l}\text { Temperature, cooling rate, } \\
\text { thermal gradient, } \\
\text { solidification rate, } \\
\text { microstructure }\end{array}$ \\
\hline Ansari et al. [21] & $\begin{array}{l}\text { Powder: Iron } \\
\text { Substrate: AISI } 1018\end{array}$ & $\begin{array}{l}\text { CCD-RSM- } \\
\text { ANOVA }\end{array}$ & $\begin{array}{l}\text { Laser power, scanning speed, } \\
\text { powder feed rate }\end{array}$ & $\begin{array}{l}\text { Single-tracks geometrical } \\
\text { characteristics, powder flow } \\
\text { efficiency, microstructure }\end{array}$ \\
\hline
\end{tabular}

Lee [13] used the Taguchi method (L18 orthogonal array) to maximize the deposition efficiency of cobalt powder alloy. The main conclusion was that the powder feed position had the greatest effect on deposition efficiency. Positioning the feed angle at $50^{\circ}$ and the powder feed rate $(0.62 \mathrm{~g} / \mathrm{s})$, as well as the laser travel speed $(6.7 \mathrm{~mm} / \mathrm{s})$ had significant effects on deposition efficiency. The type of shielding gas (Argon), the shape of the laser pulse $(1.7 / 60 \mathrm{~ms} / \mathrm{Hz})$ and the focal position $(10 \mathrm{~mm})$ had virtually no effects. These characteristics provided a deposition efficiency $12 \%$ higher.

Sun and Hao [14] employed CCD (Central Composite Design) and RSM (Response Surface Method) to develop a mathematical model to analyze the influence of laser power, laser advancement speed, and powder flow on Ti6Al4V (powder and substrate) deposition geometry, but without assessing hardness. The ANOVA method was used to establish relationships between process parameters and outputs. This ANOVA indicated that higher laser power (W) influences positively on the track width (mm). The powder flow (rev/min) had a significant effect on the coating width $(\mathrm{mm})$ and height (mm), while lower laser- 
scanning speed $(\mathrm{mm} / \mathrm{min})$ had a significant positive effect on the penetration depth $(\mathrm{mm})$. The relative percentage error of the model reached $7 \%$.

Graf et al. [15] performed a factorial analysis to determine the effect of process parameters on the cord geometry. The authors concluded that bead width $(\mathrm{mm})$ is mostly influenced by the laser power $(\mathrm{W})$, while the powder flow (g/min) has no effect at least in the range values they used. Bead height $(\mathrm{mm})$ is mainly influenced by deposition velocity ( $\mathrm{mm} / \mathrm{min})$ and powder flow. The procedure presented a good correlation between the statistical model and the experimental results obtained; residual values were lower than $0.1 \mathrm{~mm}$.

Farahmand and Kovacevic [16] used a predictive approach to assess the influence of input parameters on geometry and microhardness of the deposited beads, established the dependency relationships between the inputs and outputs and optimized the deposition process parameters of AISI H13. They concluded that when increasing the laser scanning speed (mm/s), the bead height and HAZ (heat affected zone) decreased, while microhardness increased. The powder stream (g/s) had a positive effect on bead height and the laser power (W) on the bead width. The model relative error reached $5 \%$.

Liu and Kovacevic [17] studied the effects of process parameters used on powder capture efficiency and layer geometry. They also used CCD/RSM/ANOVA to identify statistical relationships between input parameters and output variables and optimal processing parameters identification. This study used similar approach of previous works (Farahmand and Kovacevic, 2014) but using different powder materials, which could be considered an extended research. They concluded that the powder flow $(\mathrm{g} / \mathrm{min})$, the gas flow rate $(\mathrm{SCFH})$ and the interaction between the gas flow rate and the standoff distance (mm) were the most significant factors affecting the bead height $(\mathrm{mm})$, while the laser power $(\mathrm{W})$ was the factor most affected the bead width (mm). The relative error reached $\sim 12 \%$ (error of the three predicted outputs).

$\mathrm{Yu}$ et al. [18] studied through orthogonal experiments, with different deposition strategies, the process parameters optimization and performance testing of directed laser fabrication, seeking the improvement of mechanical and microstructural properties. The obtained results showed that laser power $(\mathrm{W})$, scan speed $(\mathrm{mm} / \mathrm{s})$ and powder feed rate $(\mathrm{g} / \mathrm{min})$ affect the bead geometry and consequently affect the cladding samples' quality. The authors indicated that the depth of penetration (mm) and the penetration/height ratio increased proportional to the calorific value $(\mathrm{J} / \mathrm{g})$. Higher energy values consequently have a lower powder feed rate $(\mathrm{g} / \mathrm{mm})$ or higher laser speed $(\mathrm{mm} / \mathrm{s})$, which affected the width $(\mathrm{mm})$ of the deposition.

Wu et al. [19] developed a laser-powder coupling numerical model with discontinuous powder feed rate for simulating the laser attenuation and heat transfer during laser-powder coupling process. Gaussian beam (GB) profile with powder coupling was simulated on laser attenuation and heat transport. A super GB performance simulation was compared with ideal performance and presented a good correlation. However, the mean particle intensity under these two conditions varied $50 \%$. A maximum error of $11 \%$ was reached.

Huang et al. [20] studied the process parameters correlation with the thermal characteristics for microstructure rapid prediction of laser powder-fed additive manufacturing (LPFAM). An analytical thermal model that couples the powder mass flow (g/min) and laser heat flux was used for analyzing the thermal characteristics and the solidification parameters. The solidification parameters were combined with the substructure scale solutions for microstructure prediction and finally the experiments of LPFAM were conducted to validate the correlation. The predicted microstructure showed reasonable agreement with the experimental observations (error was not quantified) for deposited material under different scanning speeds (mm/min). The authors declared that combining higher scanning speeds with a lower laser power (W) would result in lower energy input $\left(\mathrm{J} / \mathrm{mm}^{2}\right)$, thus, a better microstructure was achieved. However, these characteristics make the deposition height (mm) smaller, which is not appropriate when a higher height for 3D manufacturing is expected.

Ansari et al. [21] studied the laser water-atomized iron powder deposition. The experimental design and model for optimization model were implemented based on the RSM, and ANOVA was used for testing the regression model. The statistical model was developed to identify the optimal processing conditions to obtain just single tracks with minimum dilution, maximum bead height and high powder efficiency. Although, the good correlation was achieved between experimental and predicted data (95\% of confidence), the powder efficiency appeared low (20\%-40\%) due to the irregular powder particles shape. The parameter interactions at the evaluated levels, energy density per unit area $(\mathrm{J} / \mathrm{mm})$ and powder flow rate per unit area $(\mathrm{mg} / \mathrm{mm})$, had a greater impact on the layer height (maximum).

As may be noted, the process parameters studied the most by researchers include, but are not limited to, laser power, laser scanning speed, powder flow, gas feed-rate, laser beam diameter. Most of the researches explore only through statistical analysis, the effect of process parameters on the geometrical characteristics of the deposited beads. Hence, the Taguchi method, RSM, CCD, ANOVA, numerical models are the most studied.

The study of the deposition geometry not only implies the analysis of the bead height, width, and depth of penetration as the main characteristics of deposition quality when assessing the fabrication of three-dimensional objects [22]. Likewise, other important geometrical features that have been studied in lesser extent are bead height/bead width ratio, wetting angle and dilution, which represent an opportunity to be explored in this paper. 
The studies also focused on the statistical analysis of process parameters behavior and optimization after retroactively analyze the geometrical characteristics of deposited materials. However, as part of the hybrid manufacturing process planning, it is of paramount importance to achieve a complete understanding of the correlation between input parameters and the responsevariables performance. Configuring models based on reliable computational tools to predict the part geometry assessing the critical attributes which affect the part quality can contribute to control and guarantee the process stability to prevent the appearance of deviations between the designed and manufactured part (target product profile).

Some researchers have applied fuzzy logic to evaluate parameters and manufacturing processes performance. Supriadi and Manabe [23] used an adaptive fuzzy controller to enhance the dimensional accuracy of dieless tube-drawing process. They found that with the introduction of the fuzzy approach the process error variation was minimum. However, a more in-depth analysis is necessary, of how to avoid the process delay which consequently increases with increasing feeding speed, causing large errors at the beginning of the drawing process. Lin and Lin [24] used grey-fuzzy logic based on orthogonal array for optimizing the electrical discharge machining (EDM) process with multi-response. The experimental results demonstrated the effectiveness of the approach used.

$\mathrm{Wu}$ and Wang [25] presented a neuro-fuzzy approach for generating mold/die polishing sequences. The results experimentally obtained agreed with the predicted ones. Nevertheless, a source of error was possibly introduced due to the uncertainties of the surface roughness measurement since the measuring device used in the experiments had a limited measurable precision. Nagesh and Datta [22] used an artificial neural network (ANN) to predict bead geometry and penetration in shielded metal-arc welding. The model proposed presented high reliability on the evaluation of processes and parameters analyzed, but the experiment results showed a total error of $20 \%$ of difference between estimated and experimental values.

Recently, Tan et al. [26] presented a Mamdani-type fuzzy inference system to predict tensile properties of as-cast alloy. The approach used combined with genetic algorithm presented high accuracy. Genna et al. [27] developed a fuzzy decisionmaking approach to optimize laser-assisted joining process of polymer-metal hybrid structures also combined with genetic algorithm that allowing to obtain the results with a lower uncertainty level.

It was noted that no works were reported for studying the development of fuzzy approaches for predicting the geometrical characteristics and optimizing laser AISI 316 deposition process parameters, which represents a research topic to be explored.

As a preliminary study developed on the Hybrid additive-subtractive Manufacturing Process Planning (HMPP), this paper aims to evaluate and predict the AISI 316 single-bead geometrical characteristics, such as, bead height $(B h)$, bead width $(B w)$ and penetration depth $(d p)$, as well as the optimization of LMD parameters that attend the process stability and better geometrical characteristics. The predictive model was configured using fuzzy inference-based approach (FIS). The behavior of input parameters and their effect on the bead height $(B h)$, bead width $(B w)$, penetration depth $(d p)$, dilution $(d), B h / B w$ ratio and wetting angle $(w a)$ was assessed to correlate the responses with the configured predictive FIS.

\section{Experimental procedure}

In this work, a hybrid manufacturing system that integrates the additive (LMD) and subtractive (5 Axis Machining) processes is studied. However, the focus relied on the additive process as part of a preliminary study to understand how to ensure the stability of this manufacturing process. Qualitative and quantitative analysis of the effects of process input parameter variability (Lp, $\mathrm{Fl}$ and $\mathrm{Pf}$ ) on the output variables assessed $(B h, B w, d p, B h / B w$ ratio, $d$ and $w a)$ were performed. The ANOVA was used to determine the statistical correlation and influence of input parameters on output variables. The fuzzy inference modelling for $B h, B w$ and $d p$ prediction, and process parameter optimization, was shaped on MATLAB R2011b software through the Fuzzy Toolbox. In addition, 2D and 3D surface graphs were plotted to complement the analysis.

\subsection{Design of Experiment (DoE)}

The experimental design allowed the identification of process input parameters and their operating levels that directly affect the deposition quality. A factorial analysis was performed to determine all possible parameter combinations to improve the experimental effort and assess its interaction effects on the analyzed response variables $B h, B w, d p, B h / B w$ ratio, $d$ and $w a$. The factors combination and their operating levels implied that 18 experiments were performed. Two process replications were conducted aiming at maximizing the statistical analysis' reliability and correlating with the fuzzy modelling configured. Table 2 presents the studied process parameters and their operating levels.

Table 2. Process parameters and operating levels

\begin{tabular}{ccccc}
\hline Factors & Unit & \multicolumn{3}{c}{ Operating factors levels } \\
\hline Laser power (Lp) & Watts & 225 & 250 & 275 \\
Focal length (Fl) & $\mathrm{mm}$ & 4.8 & 5.0 & 5.2 \\
Powder flow (Pf) & $\mathrm{g} / \mathrm{s}$ & 9.40 & - & 13.35 \\
\hline Constant process parameters & & - & -
\end{tabular}




\begin{tabular}{ccccc} 
Nozzle gas $(\mathrm{Ng})$ & $\mathrm{L} / \mathrm{min}$ & 5 & - & - \\
Shield gas $(\mathrm{Sg})$ & $\mathrm{L} / \mathrm{min}$ & 5 & - & - \\
Carrier gas $(\mathrm{Cg})$ & $\mathrm{L} / \mathrm{min}$ & 4 & - & - \\
\hline
\end{tabular}

\subsection{Hybrid system and sample characteristics}

The experiments were conducted in a ROMI's full 5-axis DCM 620-5X Hybrid Machine equipped with an AMBIT тM deposition head with a $500 \mathrm{~W}$ maximum Ytterbium Fiber Laser, with $1070 \mathrm{~nm}$ wavelength and $1 \mathrm{~mm}$ of maximum spot diameter. Fig. 1 shows the configuration of the hybrid system and its operational axes, including the laser, shielding gas and powder feed operating principle regarding the substrate position.

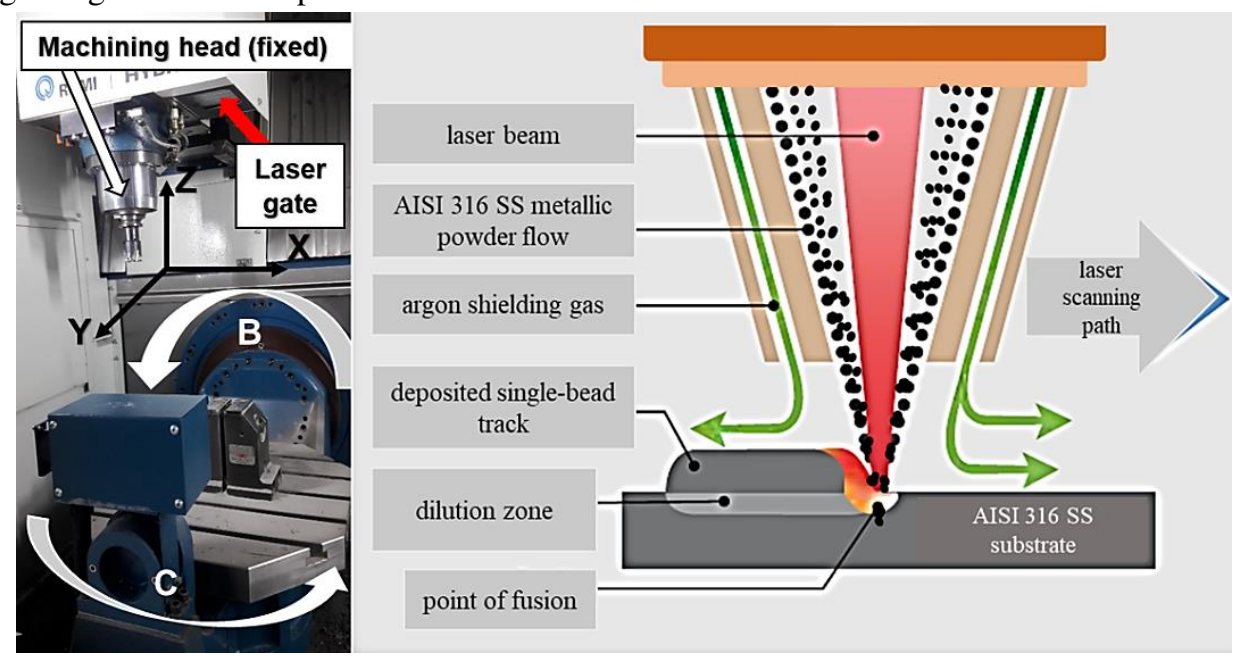

Fig. 1. Hybrid system configuration, operational axes, and laser operational principle. Adapted from ROMI [28].

The laser beam was focused on the substrate material (AISI $316 \mathrm{SS}$ ) to generate eight single beads ( $\mathrm{B}_{1}$ to $\mathrm{B}_{8}$ ) on 18 samples, combining the process parameters and their different levels (Table 2). The dimension of the samples is $\varnothing 25 \times 10 \mathrm{~mm}$. The deposition strategy followed was a one-way pattern (Zig) and the powder used was AISI 316 SS in the range of 44-106 $\mu \mathrm{m}$ particle size. Before the additive operation, the samples were face-milled, to produce a flatness surface for the deposition process. The length of each single bead was $10 \mathrm{~mm}$, the distance between the beads was $2 \mathrm{~mm}$. The powder was fed simultaneously, by a coaxial hopper focused on the laser-spot with $90^{\circ}$ orientation relative to the substrate, with argon gas. Argon gas serves as a shield to protect deposited material and preserves it from oxidation [29]. Fig. 2 (a) shows sample characteristics and dimensions (including deposited beads), and Fig. 2 (b) exemplifies the cross-section made on samples and height.

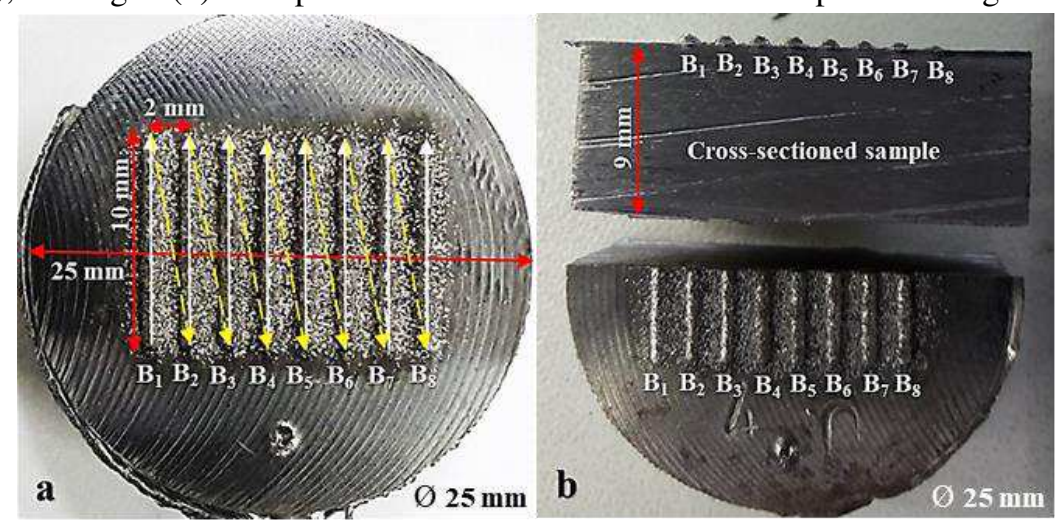

Fig. 2. (a) Sample dimensions, (b) cross section.

\subsection{Bead geometry analysis}

The metallographic work was done manually. It includes the samples cross-section, the preparation on chemical reagents and sample polishing. The measurement of $B h, B w$ and $d p$ on the substrate (Fig. 3) was done using an optical microscope Nikon Optiphot, the lens, with $1 \mathrm{~mm}$ measurement pattern inserted was x100. An average value was calculated for each variable according to the deposition conditions, which served to characterize the bead geometry. 


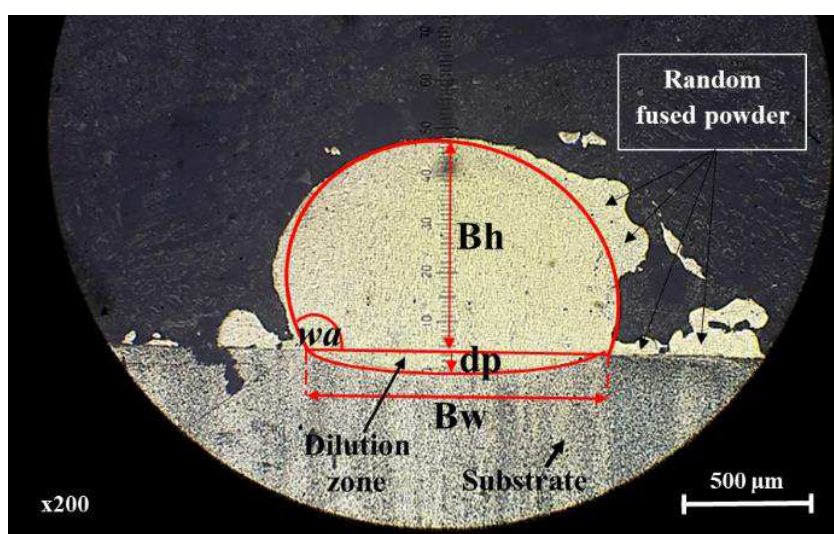

Fig. 3. Bead sample cross-section showing the bead height $(B h)$, bead width $(B w)$, depth of penetration $(d p)$, wetting angle $(w a)$ and dilution zone.

The $B h / B w$ index represents the convexity rate of the deposition. This index is discussed in Rao et al. [30]. They developed a model for pulsed gas metal arc welding (P-GMAW) to predict weld bead geometry. In this study, the-smaller-the better index implies a good geometrical characteristic. In our study, near 0.5 index is expected since it contributes to avoid overconvexed layers when overlapped. As indicated in [31], dilution $(d)$ is a measure of the bead mixing with the substrate. It represents the percentage of deposition penetration in the substrate considering the entire bead height. A higher mixing will lead to better characteristics expected as it contributes to lack of fusion avoidance. Calleja et al. [32] indicated that for wetting angles (wa) outside the range of $0-80^{\circ}$, the layers overlapping was considered defective. This defect could be conditioned for voids appearance between them. Dilution $(d)$ and wetting angle $(w a)$ were calculated following the Eq. 1 and Eq. 2, respectively, based on the deposition geometry and depth of penetration measurements.

$$
\begin{aligned}
& d(\%)=\left[\frac{d p}{B h+d p}\right] * 100 ; \\
& w a\left(\alpha^{\circ}\right)=\arcsin \left[\frac{B h}{\sqrt{B w^{2}+B h^{2}}}\right]
\end{aligned}
$$

\subsection{FIS for bead geometry prediction}

Through fuzzy logic is possible to model complex processes that contain uncertain and vague information with less resources use in terms of hardware and software and has shown to be an effective technique for addressing linguistically specified goals [33]. Gomide et al. [34] indicated the configuration of a fuzzy inference system (FIS) includes: (i) the input data, which are non-fuzzy sets of data previously defined by experts or resulting from measurements or observations; (ii) the fuzzification module, which transforms the non-fuzzy data into fuzzy sets [35] so they may become instances of input and output linguistic variables; (iii) the fuzzy reasoning module, that can be implemented commonly using the Mamdani approach [36], to determine how the rules base specified following the "if"- "then" constraints is activated for a given situation, and combined along with input fuzzy data, the module infers the control actions; and (iv) the defuzzification interface, which transforms the information correlated with the output linguistic variable into a numeric value that can be measured. This interface requires the definition of a defuzzification method [37], which allows obtaining a defuzzified output that is a logical response correlated to the system under study.

The FIS configuration to predict the deposition geometrical characteristics, namely $B h, B w$ and $d p$ is shown in Fig. 4 . To evaluate the output variables $(B h, B w, d p)$, a different fuzzy system was structured for each one.

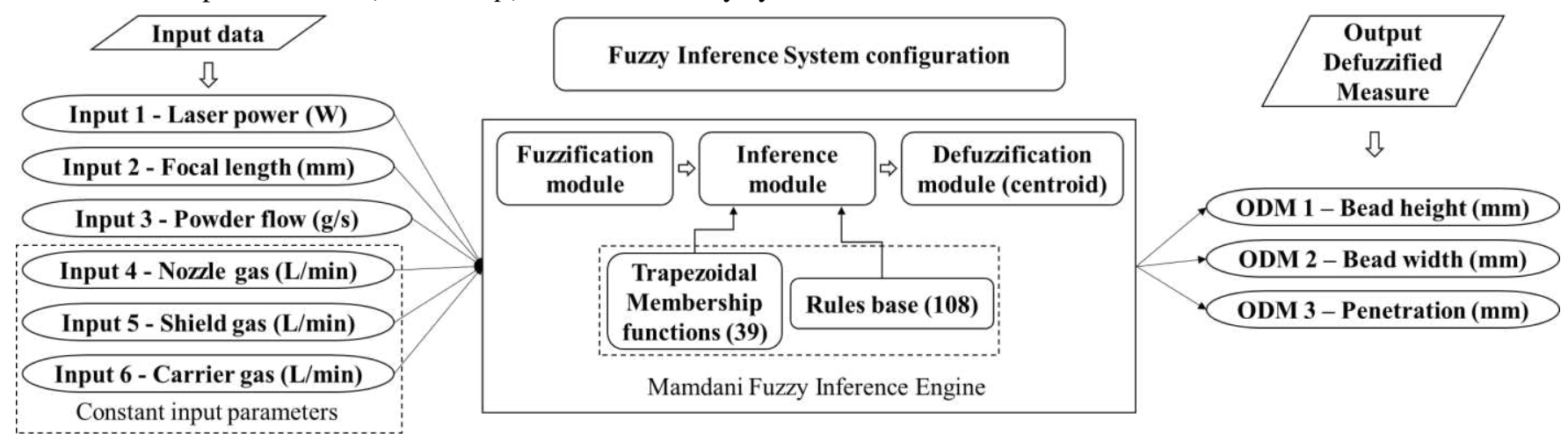

Fig. 4. FIS configuration for bead height, bead width and depth of penetration prediction.

The fuzzy sets, linguistic variables and membership functions generated for each input parameter are presented in Fig. 5, and the response-variables analyzed in Fig. 6. The trapezoidal-shape membership functions define the fuzzy sets for input 
parameters and response-variables. Concerning the input linguistic variable "laser power" were defined four input membership functions and their input fuzzy sets, which were classified as low, medium, high and very high according to the parameter operating range. Regarding input linguistic variables "focal length" and "powder flow", three membership functions and their input fuzzy sets were defined and classified as small, medium and large. For each output linguistic variables (Fig. 6), three membership functions and its output fuzzy sets were defined as low, medium and high, respectively.
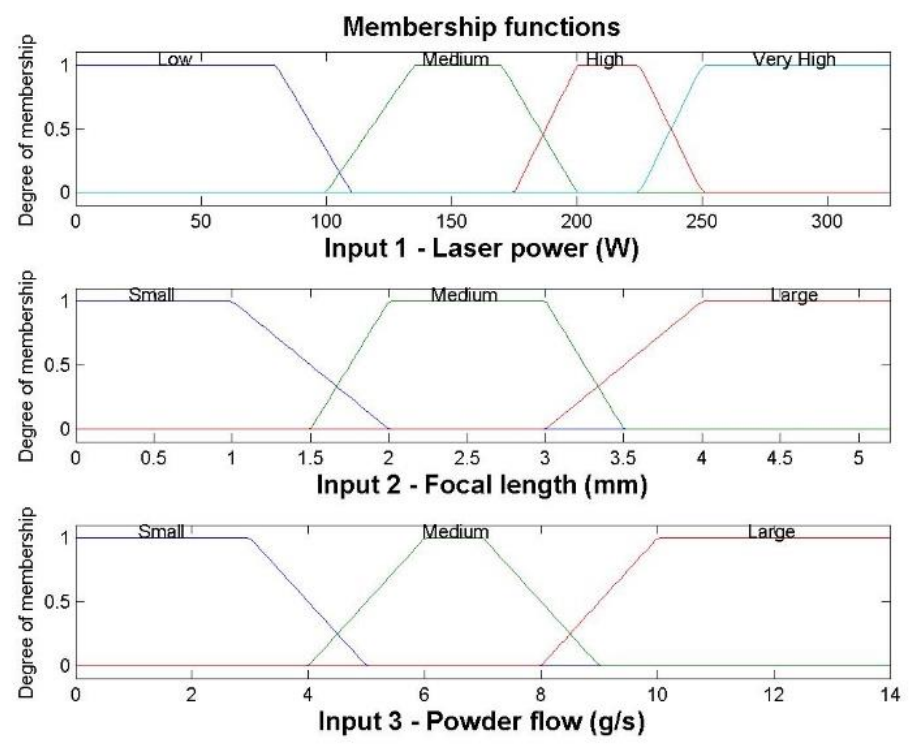

Fig. 5. Membership functions and fuzzy sets for input process parameters.
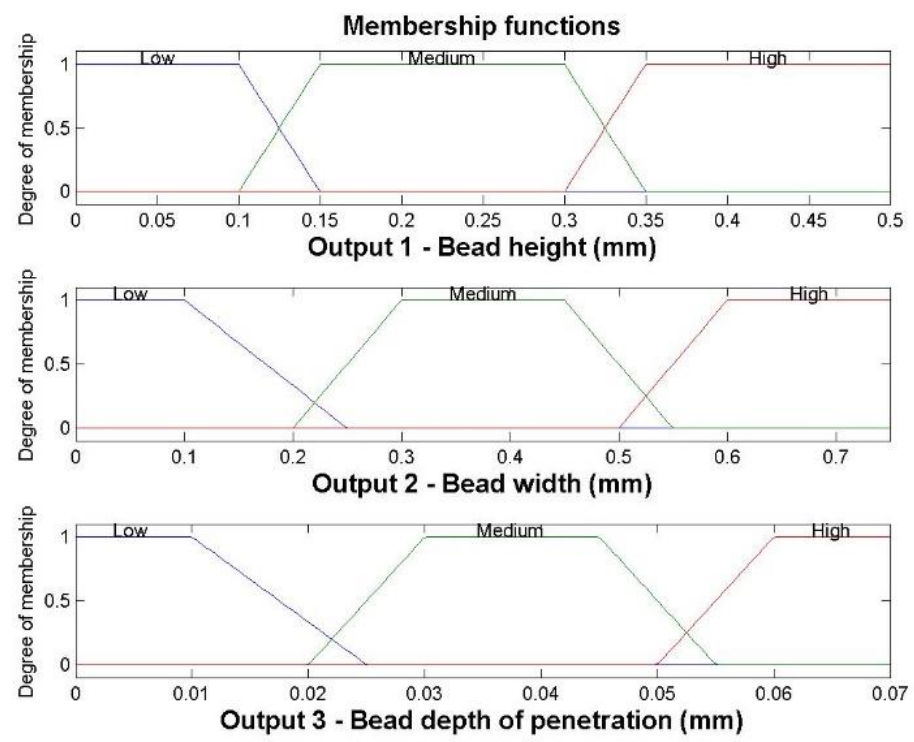

Fig. 6. Membership functions and fuzzy sets for estimated outputs.

The established rules base followed the If-then sequence for each input parameter condition (antecedent) and each responsevariable (consequent). A total of 108 rules were defined for the predictive fuzzy model that analyzed the response-variables $(B h$, $B w$ and $d p$ ). For each variable analysis, 36 rules were configured for delimiting the rule base following the "if-then" constraints (i.e., If Laser Power is 'High' and Focal Length is 'Medium' and Powder Flow is 'High' then Deposition Height is 'Acceptable'). The correlation between variables and their membership functions follows an exponential configuration $m^{n}$ to define the number of rules, where "m" represents the quantity of membership functions, and " $n$ " the quantity of variables.

The fuzzy inference module was performed using the Mamdani (max-min) method, which performs a "fuzzy reasoning", from the rules defined to generate a fuzzy value. In the last stage of the system, the defuzzification module allows converting the fuzzy output to a crisp (measurable) output.

The defuzzification method used in this paper was the so-called center of gravity (COG) method [38], as following the Eq. (3), which returns as measurable output of the center of the inferred membership function area of the parameter analyzed: 
$y_{0}=\frac{\sum y \mu_{x}(y)}{\sum \mu_{x}(y)}$

Where, $y_{0}$ is the defuzzified output of the predicted response variables; $y$ is the variable center value of fuzzy regions and $\mu_{x}(y)$ the aggregated membership functions. MATLAB offers the possibility to choose the defuzzification method, which facilitate the computational processing. In this article, the FIS predicted values of bead height $(B h)$, bead width $(B w)$ and depth of penetration $(d p)$ for each deposition condition studied were called "output defuzzified measure" (ODM) and compared along with the experimental analysis.

\subsection{FIS for process parameter optimization}

A new fuzzy system (Fig. 7) was structured to determine which LMD process parameter operating levels simulate the best performance. The inputs of this system were defined from the response-variables $(B h, B w$ and $d p)$ predicted from the previous fuzzy system (Fig. 4).

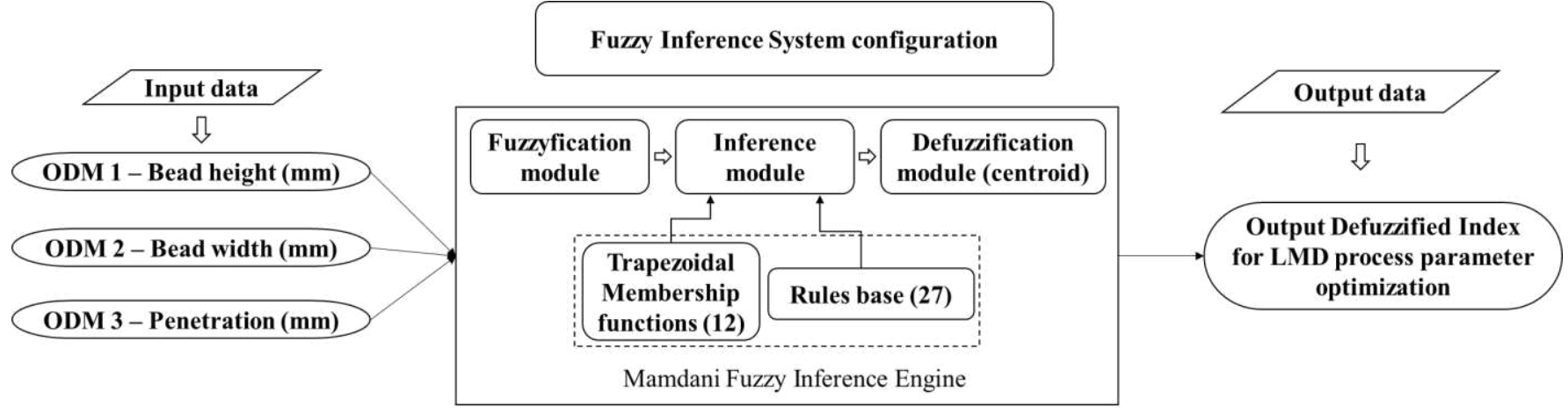

Fig. 7. FIS configuration for LMD process parameter optimization.

The greater height, width, and depth of penetration, the better geometric feature is expected. Given the precept "higher-thebetter", the ODM for each response-variable was normalized by the Eq. (4) as established in [39].

${ }^{*} N i(k)=\frac{O D M i(k)-\min O D M i(k)}{\operatorname{maxODMi}(k)-\operatorname{minODMi}(k)} ;$

Where, ${ }^{*} N_{i}(k)$ is the normalized value, $O D M_{i}(k)$ is the output value for the analyzed response $k$ from experiment $i$.

The same procedure of the previous system (Fig. 4) was followed to model the optimizing fuzzy system of Fig. 7. The fuzzy sets, linguistics variables and membership functions of the system inputs and outputs (ODI - output defuzzified index) are presented in Fig. 8. For input linguistic variable "bead height", three input membership functions and their input fuzzy sets were defined and classified as low, medium and high. Regarding the input linguistic variable "bead width", also three input membership functions and their input fuzzy sets were defined and classified in small, medium and suitable. Concerning the input linguistic variable "depth of penetration", also three input membership functions and their input fuzzy sets were defined and classified as unsuitable, acceptable and suitable. The ODI membership functions and their fuzzy sets were classified as low, medium and high.
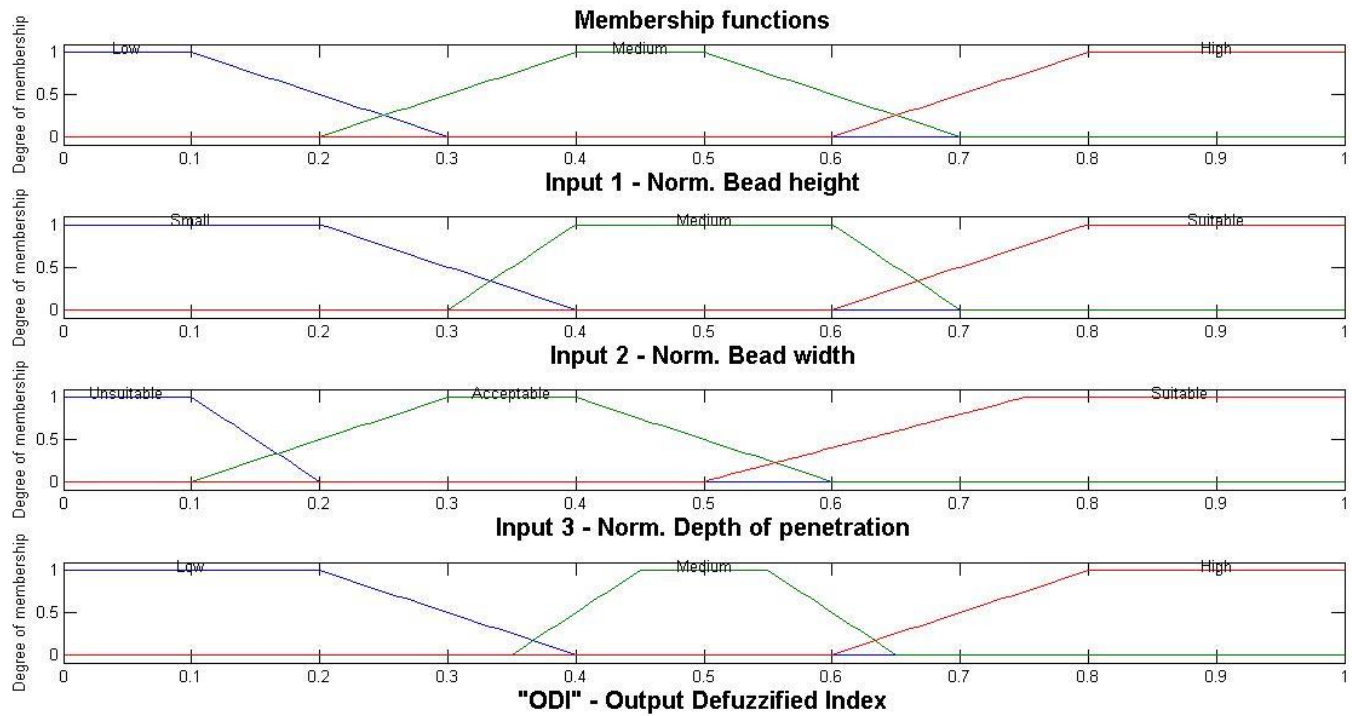
Fig. 8. Membership functions and fuzzy sets for Membership functions and fuzzy sets for input normalized parameters bead height, bead width and depth of penetration, and estimated output index.

Twenty-seven (27) rules were structured for this new fuzzy system based on the precept that the better performance of process parameters will respond to a higher output value. The inference system used was Mamdani and the COG defuzzification method. The FIS output to optimize the process parameters was called "output defuzzified index" (ODI). This index behaves in the range from $0-1$. The higher ODI value indicates that a given deposition condition is the better one that simulates the LMD process.

\section{Results and discussion}

\subsection{Effect of process parameter interaction on deposition geometry}

Table 3 summarizes the measured mean values for bead height $(B h)$, bead width $(B w)$, depth of penetration $(d p)$, bead height/bead width $(\mathrm{Bh} / \mathrm{Bw})$ ratio, dilution $(d)$ and wetting angle $(w a)$ for each deposition condition. Mean values were obtained from the measured values of the 18 experiments and its replications.

From a separate evaluation of each response, it can be noted that experiments performed with powder flow equal to 13.35 $\mathrm{g} / \mathrm{s}$, the $B h$ and $B w$ increases, and the depth of penetration decreases. Dilution $(d)$ indicates the percentage of deposited powder's penetration in the substrate, the behavior ranged from $8 \%$ to $22 \%$. The highest $d$ percentage was achieved at Lp $=275 \mathrm{~W}, 5$ $\mathrm{mm}$ and $5.2 \mathrm{~mm}$ of focal length $(\mathrm{Fl})$ and $\mathrm{Pf}=9.40 \mathrm{~g} / \mathrm{s}$. The highest $w a$ was obtained in experiment 2 with a value of $35^{\circ}$ with a $\mathrm{Lp}=225 \mathrm{~W}, \mathrm{Fl}=4.8 \mathrm{~mm}$ and $\mathrm{Pf}=13.35 \mathrm{~g} / \mathrm{s}$. The greatest height was observed with $\mathrm{Lp}=275 \mathrm{~W}, \mathrm{Fl}=5 \mathrm{~mm}$ and $\mathrm{Pf}=13.35 \mathrm{~g} / \mathrm{s}$. The largest width was reached at $\mathrm{Lp}=275 \mathrm{~W}, \mathrm{Fl}=4.8 \mathrm{~mm}$ and $\mathrm{Pf}=13.35 \mathrm{~g} / \mathrm{s}$. Penetration $(d p)$ was highest at $\mathrm{Lp}=275 \mathrm{~W}, \mathrm{Fl}$ $=5 \mathrm{~mm}$ and $\mathrm{Pf}=9.40 \mathrm{~g} / \mathrm{s}$. The $\mathrm{Bh} / \mathrm{Bw}$ indexes were measured between to $0.339-0.698$, varying $51 \%$ approximately and the indexes values next to 0.5 were reached in the experiments 1,7 and 13 .

Table 3. Mean values of response-variables analyzed for each experimental condition

\begin{tabular}{cccccccccc}
\hline Run & $\mathbf{L p}(\mathbf{W})$ & $\mathbf{F l}(\mathbf{m m})$ & $\mathbf{P f}(\mathbf{g} / \mathbf{s})$ & $\boldsymbol{B h}(\mathbf{m m})$ & $\boldsymbol{B} \boldsymbol{w}(\mathbf{m m})$ & $\boldsymbol{d} \boldsymbol{p}(\mathbf{m m})$ & $\boldsymbol{B h} / \boldsymbol{B} \boldsymbol{w}$ ratio & $\boldsymbol{d}(\boldsymbol{\%})$ & $\boldsymbol{w a}\left(\boldsymbol{\alpha}^{\circ}\right)$ \\
\hline $\mathbf{1}$ & 225 & 4,8 & 9.40 & 0,266 & 0,516 & 0,054 & 0,516 & 17 & 27 \\
$\mathbf{2}$ & 225 & 4,8 & 13.35 & 0,414 & 0,593 & 0,031 & 0,698 & 7 & 35 \\
$\mathbf{3}$ & 250 & 4,8 & 9.40 & 0,259 & 0,603 & 0,039 & 0,430 & 13 & 23 \\
$\mathbf{4}$ & 250 & 4,8 & 13.35 & 0,383 & 0,712 & 0,033 & 0,538 & 8 & 28 \\
$\mathbf{5}$ & 275 & 4,8 & 9.40 & 0,260 & 0,662 & 0,064 & 0,393 & 20 & 21 \\
$\mathbf{6}$ & 275 & 4,8 & 13.35 & 0,436 & 0,743 & 0,054 & 0,587 & 11 & 30 \\
$\mathbf{7}$ & 225 & 5 & 9.40 & 0,199 & 0,551 & 0,048 & 0,361 & 19 & 20 \\
$\mathbf{8}$ & 225 & 5 & 13.35 & 0,400 & 0,626 & 0,039 & 0,639 & 9 & 33 \\
$\mathbf{9}$ & 250 & 5 & 9.40 & 0,253 & 0,613 & 0,056 & 0,413 & 18 & 22 \\
$\mathbf{1 0}$ & 250 & 5 & 13.35 & 0,392 & 0,657 & 0,048 & 0,597 & 11 & 31 \\
$\mathbf{1 1}$ & 275 & 5 & 9.40 & 0,248 & 0,679 & 0,069 & 0,365 & 22 & 20 \\
$\mathbf{1 2}$ & 275 & 5 & 13.35 & 0,454 & 0,688 & 0,061 & 0,660 & 12 & 33 \\
$\mathbf{1 3}$ & 225 & 5,2 & 9.40 & 0,244 & 0,528 & 0,050 & 0,462 & 17 & 25 \\
$\mathbf{1 4}$ & 225 & 5,2 & 13.35 & 0,377 & 0,611 & 0,038 & 0,617 & 9 & 32 \\
$\mathbf{1 5}$ & 250 & 5,2 & 9.40 & 0,215 & 0,606 & 0,059 & 0,355 & 22 & 20 \\
$\mathbf{1 6}$ & 250 & 5,2 & 13.35 & 0,418 & 0,634 & 0,049 & 0,659 & 10 & 33 \\
$\mathbf{1 7}$ & 275 & 5,2 & 9.40 & 0,231 & 0,686 & 0,067 & 0,337 & 22 & 19 \\
$\mathbf{1 8}$ & 275 & 5,2 & 13.35 & 0,416 & 0,679 & 0,061 & 0,613 & 13 & 31 \\
\hline
\end{tabular}

\subsection{Analysis of variance (ANOVA)}

The ANOVA was used to evaluate which parameters have a significant influence on the process and on the evaluated variables. Tables 4 to 9 present this analysis. $P$ values $<0.05$ indicate that the parameter effect on the evaluated output variables is significant at a $95 \%$ confidence level. Tables $4,7,8$ and 9 show that the powder flow seems to have greater influence on the $B h, B h / B w$ ratio, $d$ and $w a$. For $B w$ and $d p$, laser power seems to have a greater significance (Tables 5 and 6).

Table 4. ANOVA for bead height $(B h)$ response

\begin{tabular}{ccccccccc}
\hline Source & $S S$ & Error & $d f$ & Error & $M S$ & Error & $F$ & $P$-value \\
\hline
\end{tabular}




\begin{tabular}{llllllllc}
\hline Laser power - Lp (W) & 0,0020 & 0,1292 & 2 & 15 & 0,0010 & 0,0086 & 0,1158 & 0,8909 \\
Focal length - Fl (mm) & 0,0003 & 0,1309 & 2 & 15 & 0,0002 & 0,0087 & 0,0171 & 0,9830 \\
Powder flow - Pf (g/s) & 0,1247 & 0,0065 & 1 & 16 & 0,1247 & 0,0004 & 307,0088 & $7,28 \mathrm{e}-12$ \\
\hline
\end{tabular}

Table 5. ANOVA for bead width $(B w)$ response

\begin{tabular}{ccccccccc}
\hline Source & $\boldsymbol{S S}$ & Error & $\boldsymbol{d} \boldsymbol{f}$ & Error & $\boldsymbol{M S}$ & Error & $\boldsymbol{F}$ & $\boldsymbol{P}$-value \\
\hline Laser power - Lp (W) & 0,0311 & 0,0266 & 2 & 15 & 0,0156 & 0,0018 & 8,7570 & 0,0030 \\
Focal length - Fl (mm) & $3,5 \mathrm{e}-05$ & 0,0577 & 2 & 15 & $1,8 \mathrm{e}-05$ & 0,0038 & 0,0046 & 0,9954 \\
Powder flow - Pf (g/s) & 0,0098 & 0,0479 & 1 & 16 & 0,0098 & 0,0030 & 3,2881 & 0,0886 \\
\hline
\end{tabular}

Table 6. ANOVA for depth of penetration $(d p)$ response

\begin{tabular}{ccccccccc}
\hline Source & $\boldsymbol{S S}$ & Error & $\boldsymbol{d f}$ & Error & $\boldsymbol{M S}$ & Error & $\boldsymbol{F}$ & $\boldsymbol{P}$-value \\
\hline Laser power - Lp (W) & 0,0009 & 0,0014 & 2 & 15 & 0,0005 & $9,2 \mathrm{e}-05$ & 4,9721 & 0,0221 \\
Focal length - Fl (mm) & 0,0002 & 0,0020 & 2 & 15 & 0,0001 & 0,0001 & 0,9104 & 0,4235 \\
Powder flow - Pf (g/s) & 0,0004 & 0,0018 & 1 & 16 & 0,0004 & 0,0001 & 3,8206 & 0,0683 \\
\hline
\end{tabular}

Table 7. ANOVA for $B h / B w$ ratio response

\begin{tabular}{ccccccccc}
\hline Source & $\boldsymbol{S S}$ & Error & $\boldsymbol{d f}$ & Error & $\boldsymbol{M S}$ & Error & $\boldsymbol{F}$ & $\boldsymbol{P}$-value \\
\hline Laser power - Lp (W) & 0,0115 & 0,2504 & 2 & 15 & 0,0057 & 0,0167 & 0,3432 & 0,7149 \\
Focal length - Fl (mm) & 0,0017 & 0,2602 & 2 & 15 & 0,0008 & 0,0174 & 0,0486 & 0,9527 \\
Powder flow - Pf (g/s) & 0,2169 & 0,0449 & 1 & 16 & 0,2169 & 0,0028 & 77,2594 & $1,6 \mathrm{e}-07$ \\
\hline
\end{tabular}

Table 8. ANOVA for dilution $(d)$ response

\begin{tabular}{ccccccccc}
\hline Source & $\boldsymbol{S S}$ & Error & $\boldsymbol{d f}$ & Error & $\boldsymbol{M S}$ & Error & $\boldsymbol{F}$ & $\boldsymbol{P}$-value \\
\hline Laser power - Lp (W) & 45,7777 & 412,6666 & 2 & 15 & 22,8888 & 27,5111 & 0,8319 & 0,4543 \\
Focal length - Fl (mm) & 28,7777 & 429,6666 & 2 & 15 & 14,3888 & 28,6444 & 0,5023 & 0,6149 \\
Powder flow - Pf (g/s) & 355,5555 & 102,8888 & 1 & 16 & 355,5555 & 6,4305 & 55,2915 & $1,41 \mathrm{e}-06$ \\
\hline
\end{tabular}

Table 9. ANOVA for wetting angle $(w a)$ response

\begin{tabular}{ccccccccc}
\hline Source & $\boldsymbol{S S}$ & Error & $\boldsymbol{d} \boldsymbol{f}$ & Error & $\boldsymbol{M S}$ & Error & $\boldsymbol{F}$ & $\boldsymbol{P}$-value \\
\hline Laser power - Lp (W) & 31 & 499,5 & 2 & 15 & 15,5 & 33,3 & 0,4654 & 0,6366 \\
Focal length - Fl (mm) & 2,3333 & 528,1666 & 2 & 15 & 1,1666 & 35,2111 & 0,0331 & 0,9674 \\
Powder flow - Pf (g/s) & 440,0555 & 90,4444 & 1 & 16 & 440,0555 & 5,6527 & 77,8475 & $1,5 \mathrm{e}-07$ \\
\hline
\end{tabular}

Fig. 9 illustrates the mean values of $B h, B w$ and $d p$, and Fig. 10, the mean values of the mean values of $B h / B w$ ratio, dilution $(d)$ and wetting angle $(w a)$, for each interaction of the input parameters $\mathrm{Lp}(\mathrm{W})$ and $\mathrm{Pf}(\mathrm{g} / \mathrm{s})$.

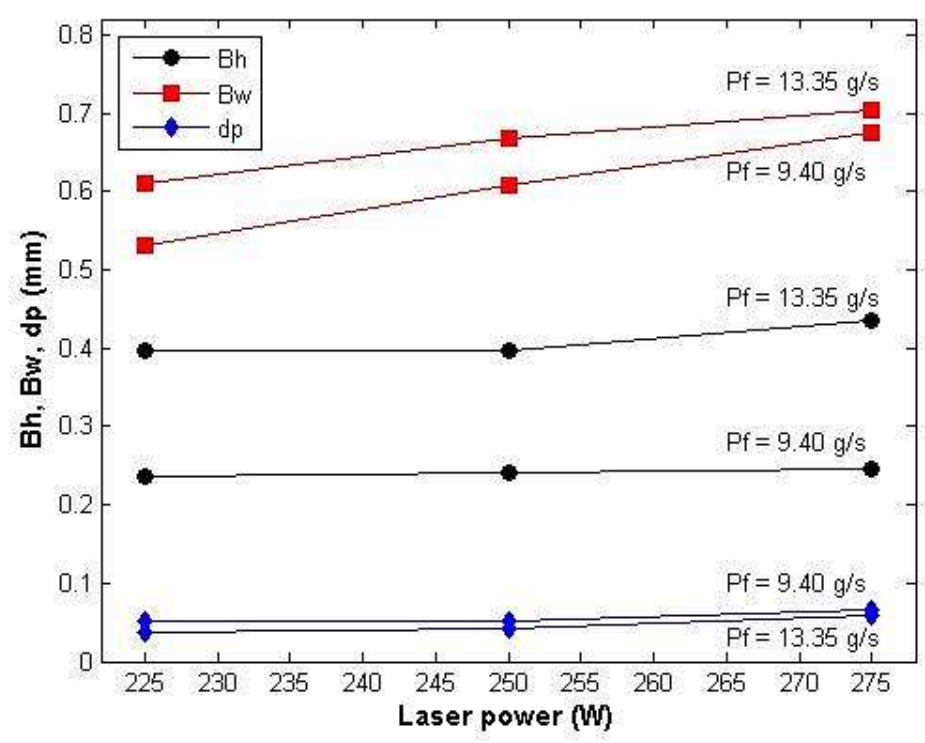

Fig. 9. (a) Mean values of $B h, B w$ and $d p$ for $\mathrm{Lp}(\mathrm{W})$ and $\mathrm{Pf}(\mathrm{g} / \mathrm{s})$ interaction. 

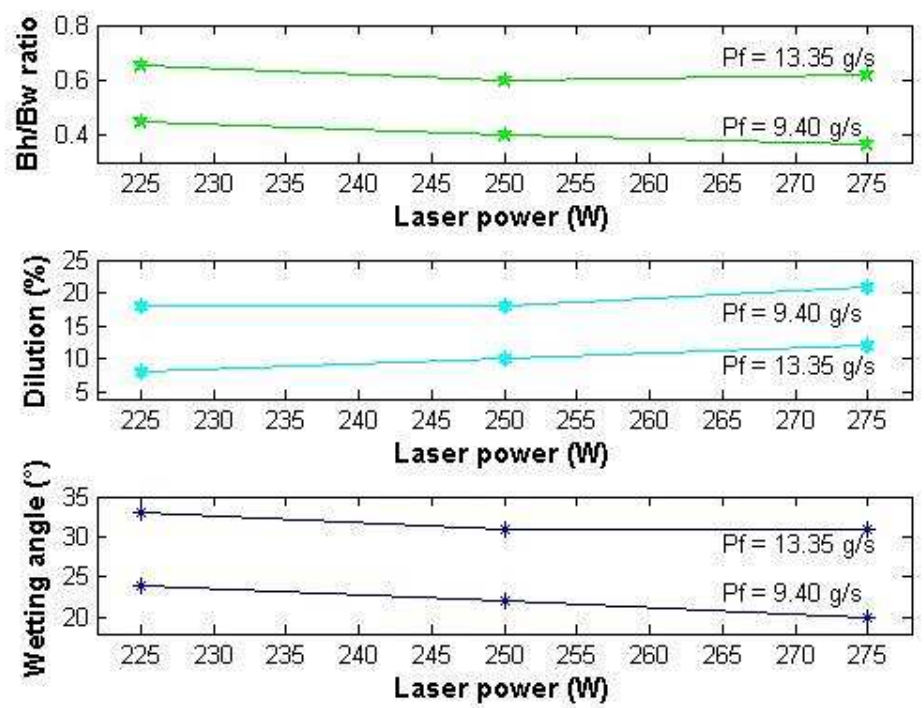

Fig. 10. Mean values of $B h / B w$ ratio, dilution $(d)$ and wetting angle $(w a)$ for $\mathrm{Lp}(\mathrm{W})$ and $\mathrm{Pf}(\mathrm{g} / \mathrm{s})$ interaction.

Fig. 11 shows eight cross-sectioned beads to illustrate the general variation trend on the deposited geometry (deposition initiating from left to right). It was noticed that in each sample the first three beads had lower height but with greater depth of penetration, accounting for approximately 31-48\% of penetration in relation to height. The opposite is true for the remaining five beads, showing a variation between $8-13 \%$. This may be conditioned by the initial oscillation level of powder flow, which suffers a $12 \mathrm{~s}$ delay to be stabilized before initiating the material deposition.

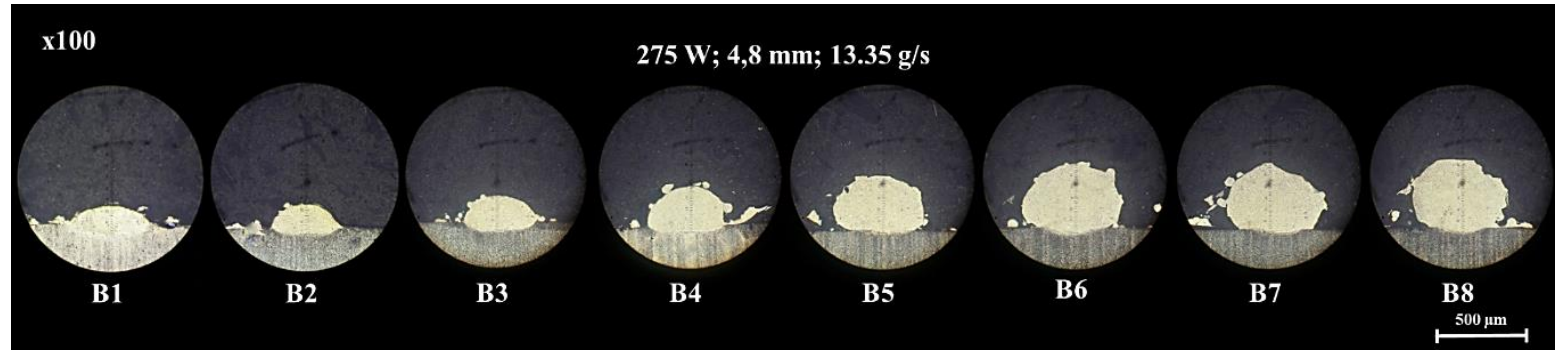

Fig. 11. Cross section of eight strands generated in the LMD process.

The previous results analyzed (section 3.1 and 3.2) are in line with the results showed in previous papers discussed [14; 15; $17 ; 18 ; 21 ; 30-32]$.

\subsection{Fuzzy inference for $B h, B w, d p$ prediction and LMD process parameters optimization}

Fig. 12 presents the rule viewer toolbox of the ODM of $B h$ for the development of the predictive fuzzy inference system. The rules-viewer is used to determine each expected output according to each experimental condition performed. The first three columns show the three input process parameters, and the fourth column indicates the ODM of the response-variable (bead height). Using experiment 18 (Table 3) as example, it can be noted that for $\mathrm{Lp}=275 \mathrm{~W}, \mathrm{Fl}=5.2 \mathrm{~mm}$ and $\mathrm{Pf}=13.35 \mathrm{~g} / \mathrm{s}$, the ODM for bead height is $0.413 \mathrm{~mm}$. Comparing the model results with the experimental value obtained $(0.416 \mathrm{~mm})$, the relative error is $0.72 \%$, which can be considered low. The predicted $B w$ and $d p$ values were also analyzed from a rule viewer like Fig. 12. Although the focal length was considered part of the fuzzy model since it was settled for operating at three levels, the ANOVA proved it had no influence on the responses evaluated. 


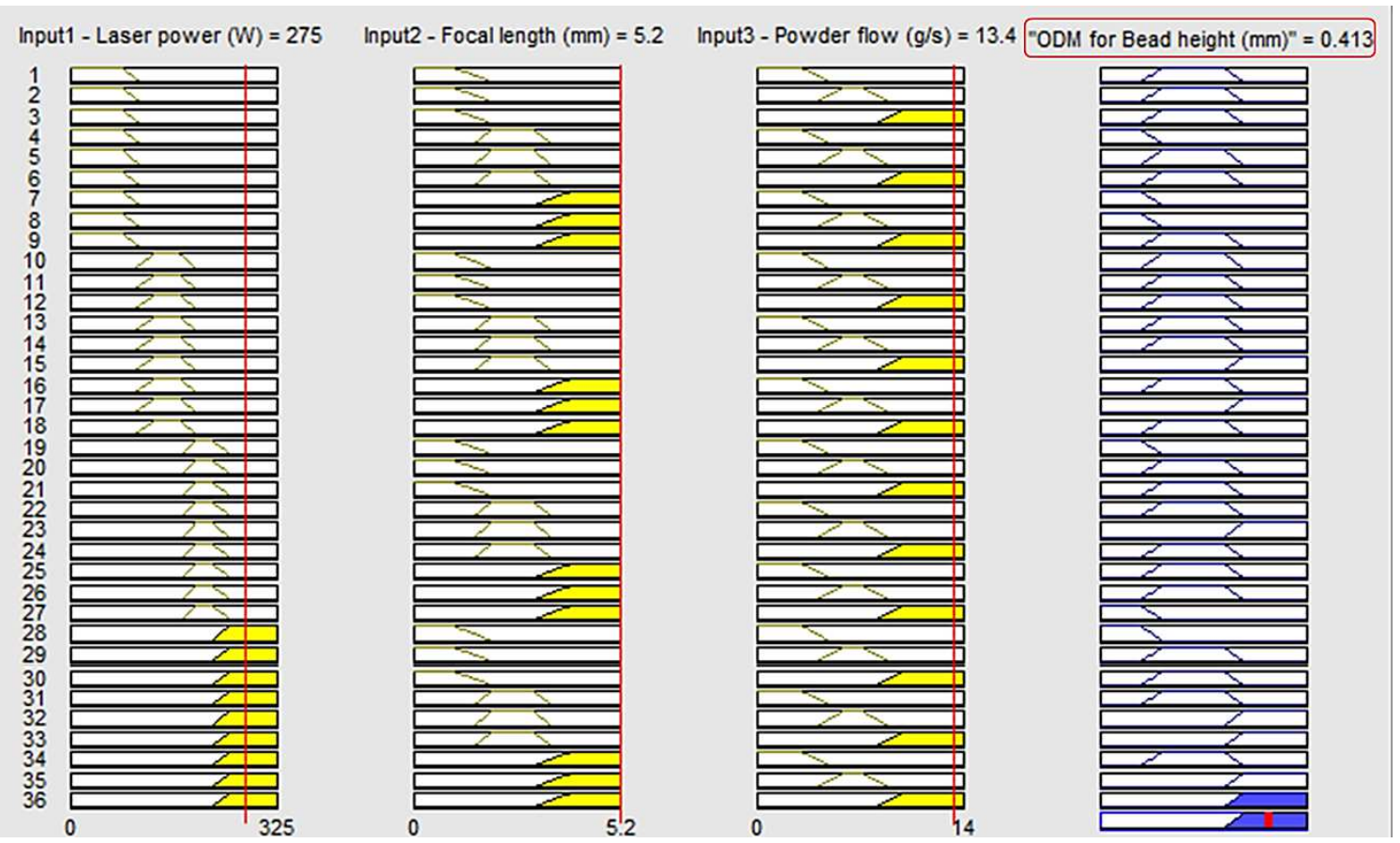

Fig. 12. Rules viewer and ODM of predicted bead height.

Fig. 13 presents the 3D maps obtained during the predictive fuzzy modeling. Each map shows the interaction of the two process parameters (Lp and Pf) that has greater incidence on the outputs $(B h, B w$ and $d p)$ according to the ANOVA. Fig 13 shows the ODM 3D maps in (a) for predicted $B h$, (b) for predicted $B w$ and (c) for predicted $d p$. The region with maximum predicted value for the evaluated output variables is represented with the strongest colored surface.

(a)

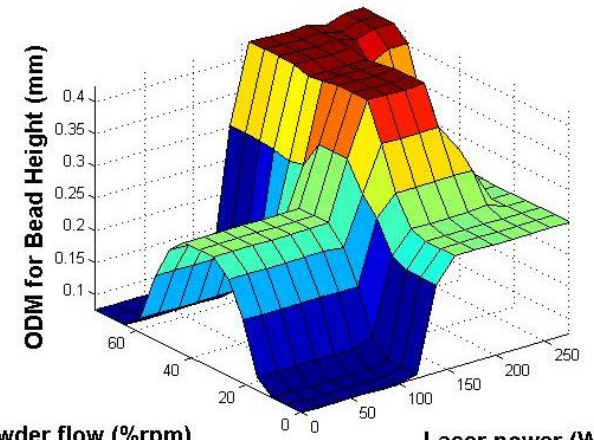

Powder flow (\%rpm)

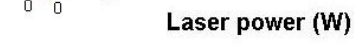

(b)

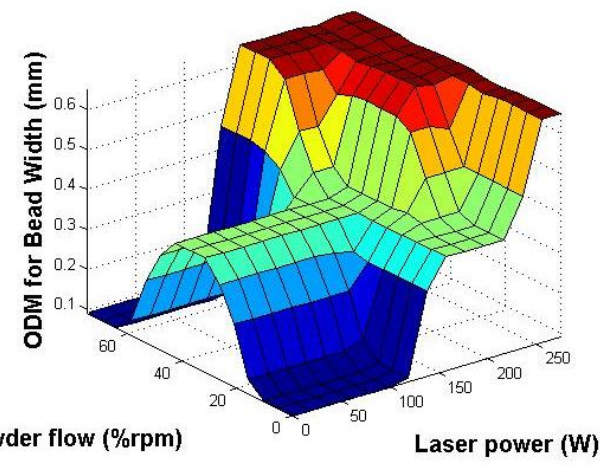

(c) ${ }^{\text {Pow }}$

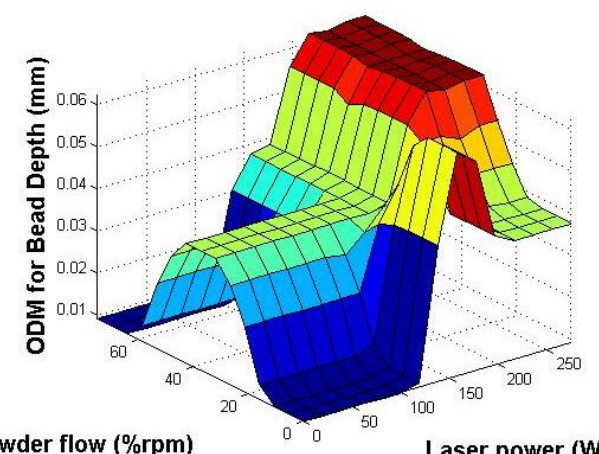

Laser power $(W)$

Fig. 13. ODM 3D maps for (a) predicted $B h$, (b) for predicted $B w$, (c) for predicted $d p$.

Fig. 14 indicates rule viewer toolbox of the ODI obtained from the normalized values of height, width, and depth of penetration as part of the fuzzy system for LMD process parameters optimization. As an example, experiment 18 was indicated again to exemplify that for height index 0.149 , width index 0.282 and depth of penetration index 0.211 , the output index was 0.171. The maximum ODI indicates that the fuzzy system predicts the LMD process parameters for that experiment has the best performance. 


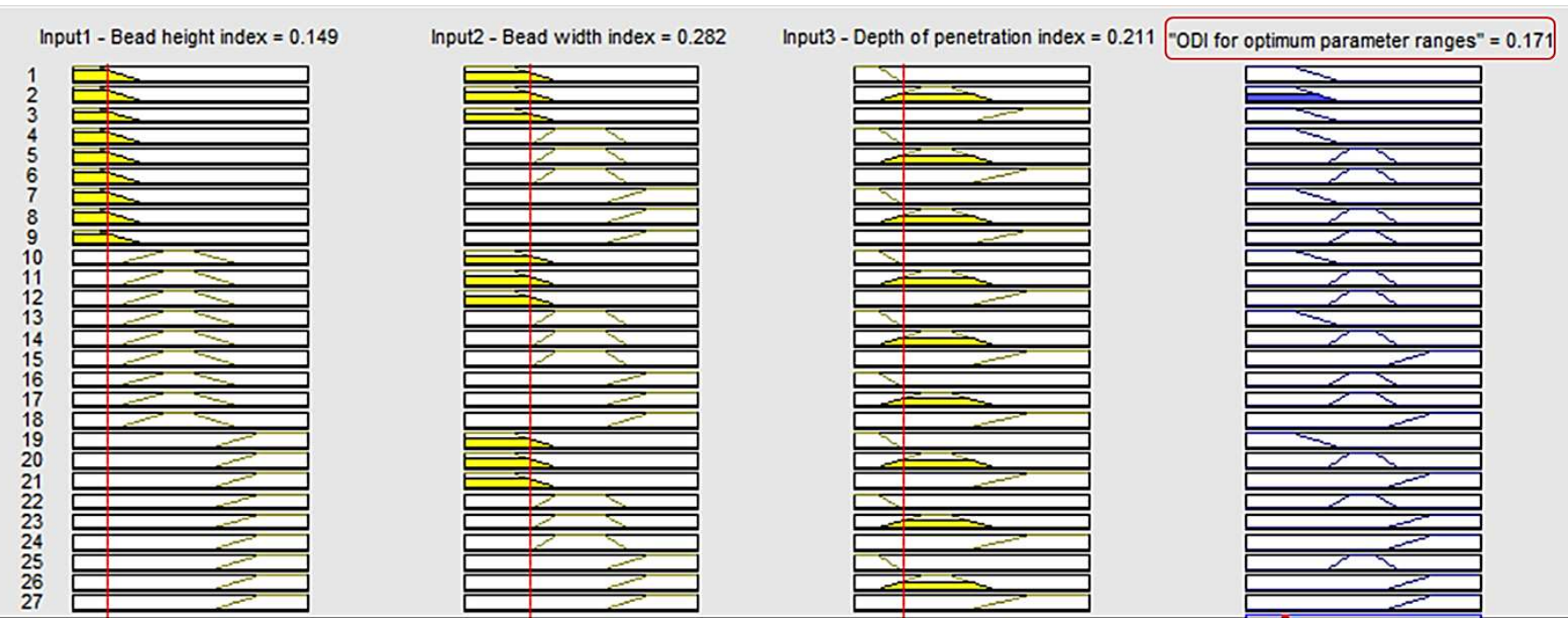

Fig. 14. Rules viewer and ODI for optimum process parameter ranges.

Table 10 presents the results obtained from the fuzzy systems for prediction of bead height, width and penetration depth indicated in ODM columns, as well as, for simulation of the best performing LMD process parameters as shown in ODI column. The maximum ODI was 0.845 , which corresponds to experiment 9 , with $250 \mathrm{~W}$ of laser power, $5 \mathrm{~mm}$ of focal length and 9.40 $\mathrm{g} / \mathrm{s}$ of powder flow.

Table 10. Experimental values vs. predicted ODM and error; normalized indexes of $B h, B w, d p$ and ODI for LMD process parameter optimization

\begin{tabular}{|c|c|c|c|c|c|c|c|c|c|c|c|c|c|}
\hline Run & $\begin{array}{c}B h \\
(\mathbf{m m})\end{array}$ & $\begin{array}{l}\text { ODM } \\
(\mathbf{m m})\end{array}$ & $\begin{array}{c}\text { Error } \\
(\%)\end{array}$ & $\begin{array}{c}\text { Norm. } \\
\text { Bh }\end{array}$ & $\begin{array}{c}B w \\
(\mathbf{m m})\end{array}$ & $\begin{array}{l}\text { ODM } \\
(\mathbf{m m})\end{array}$ & $\begin{array}{c}\text { Error } \\
(\%)\end{array}$ & $\begin{array}{c}\text { Norm. } \\
\text { Bw }\end{array}$ & $\begin{array}{c}d p \\
(\mathrm{~mm})\end{array}$ & $\begin{array}{l}\text { ODM } \\
(\mathrm{mm})\end{array}$ & $\begin{array}{c}\text { Error } \\
(\%)\end{array}$ & $\begin{array}{c}\text { Norm. } \\
\quad d p\end{array}$ & $O D I$ \\
\hline 1 & 0,266 & 0,252 & 5,26 & 0,737 & 0,516 & 0,514 & 0,39 & 1,000 & 0,054 & 0,061 & $-12,96$ & 0,395 & 0,834 \\
\hline 2 & 0,414 & 0,417 & $-0,72$ & 0,157 & 0,593 & 0,590 & 0,51 & 0,661 & 0,031 & 0,032 & $-3,23$ & 1,000 & 0,500 \\
\hline 3 & 0,259 & 0,250 & 3,47 & 0,765 & 0,603 & 0,590 & 2,16 & 0,617 & 0,039 & 0,032 & 17,95 & 0,789 & 0,840 \\
\hline 4 & 0,383 & 0,385 & $-0,52$ & 0,278 & 0,712 & 0,700 & 1,69 & 0,137 & 0,033 & 0,032 & 3,03 & 0,947 & 0,409 \\
\hline 5 & 0,260 & 0,252 & 3,08 & 0,761 & 0,662 & 0,650 & 1,81 & 0,357 & 0,064 & 0,062 & 3,13 & 0,132 & 0,476 \\
\hline 6 & 0,436 & 0,424 & 2,75 & 0,071 & 0,743 & 0,745 & $-0,27$ & 0,000 & 0,054 & 0,056 & $-3,70$ & 0,395 & 0,153 \\
\hline 7 & 0,199 & 0,210 & $-5,53$ & 1,000 & 0,551 & 0,540 & 2,00 & 0,846 & 0,048 & 0,050 & $-4,17$ & 0,553 & 0,814 \\
\hline 8 & 0,400 & 0,405 & $-1,25$ & 0,212 & 0,626 & 0,635 & $-1,44$ & 0,515 & 0,039 & 0,038 & 2,56 & 0,789 & 0,552 \\
\hline 9 & 0,253 & 0,250 & 1,19 & $\mathbf{0 , 7 8 8}$ & 0,613 & 0,640 & $-4,40$ & 0,573 & 0,056 & 0,056 & 0,00 & 0,342 & 0,845 \\
\hline 10 & 0,392 & 0,385 & 1,79 & 0,243 & 0,657 & 0,650 & 1,07 & 0,379 & 0,048 & 0,050 & $-4,17$ & 0,553 & 0,570 \\
\hline 11 & 0,248 & 0,252 & $-1,61$ & 0,808 & 0,679 & 0,680 & $-0,15$ & 0,282 & 0,069 & 0,065 & 5,80 & 0,000 & 0,170 \\
\hline 12 & 0,454 & 0,448 & 1,32 & 0,000 & 0,688 & 0,650 & 5,52 & 0,242 & 0,061 & 0,056 & 8,20 & 0,211 & 0,171 \\
\hline 13 & 0,244 & 0,250 & $-2,46$ & 0,824 & 0,528 & 0,540 & $-2,27$ & 0,947 & 0,050 & 0,056 & $-12,00$ & 0,500 & 0,826 \\
\hline 14 & 0,377 & 0,380 & $-0,80$ & 0,302 & 0,611 & 0,635 & $-3,93$ & 0,581 & 0,038 & 0,038 & 0,00 & 0,816 & 0,827 \\
\hline 15 & 0,215 & 0,210 & 2,33 & 0,937 & 0,606 & 0,635 & $-4,79$ & 0,604 & 0,059 & 0,056 & 5,08 & 0,263 & 0,840 \\
\hline 16 & 0,418 & 0,417 & 0,24 & 0,141 & 0,634 & 0,635 & $-0,16$ & 0,480 & 0,049 & 0,050 & $-2,04$ & 0,526 & 0,500 \\
\hline 17 & 0,231 & 0,250 & $-8,23$ & 0,875 & 0,686 & 0,680 & 0,87 & 0,251 & 0,067 & 0,065 & 2,99 & 0,053 & 0,163 \\
\hline 18 & 0,416 & 0,413 & 0,72 & 0,149 & 0,679 & 0,650 & 4,27 & 0,282 & 0,061 & 0,062 & $-1,64$ & 0,211 & 0,171 \\
\hline
\end{tabular}

The comparative evaluation between the results obtained from the predictive fuzzy inference system and the experimental data is presented in Fig. 15 for $B h, B w, d p$, and Fig. 16 for $d$, wa and $B h / B w$ ratio. As the three last output variables are dependent from the ones simulated, the comparison between predicted and experimental is also presented. It can be seeing that there is a good correlation between both results. The relative error (Table 10) calculated from the experimental data and the ODM indicates that the fuzzy model presents high accuracy for $B h, B w$ and $d p$ prediction. The total error for each predicted variable ranged from $1.03 \%, 2.88 \%$ and $4.8 \%$, while the average error was between 0.06 and $0.27 \%$, which is very low. 

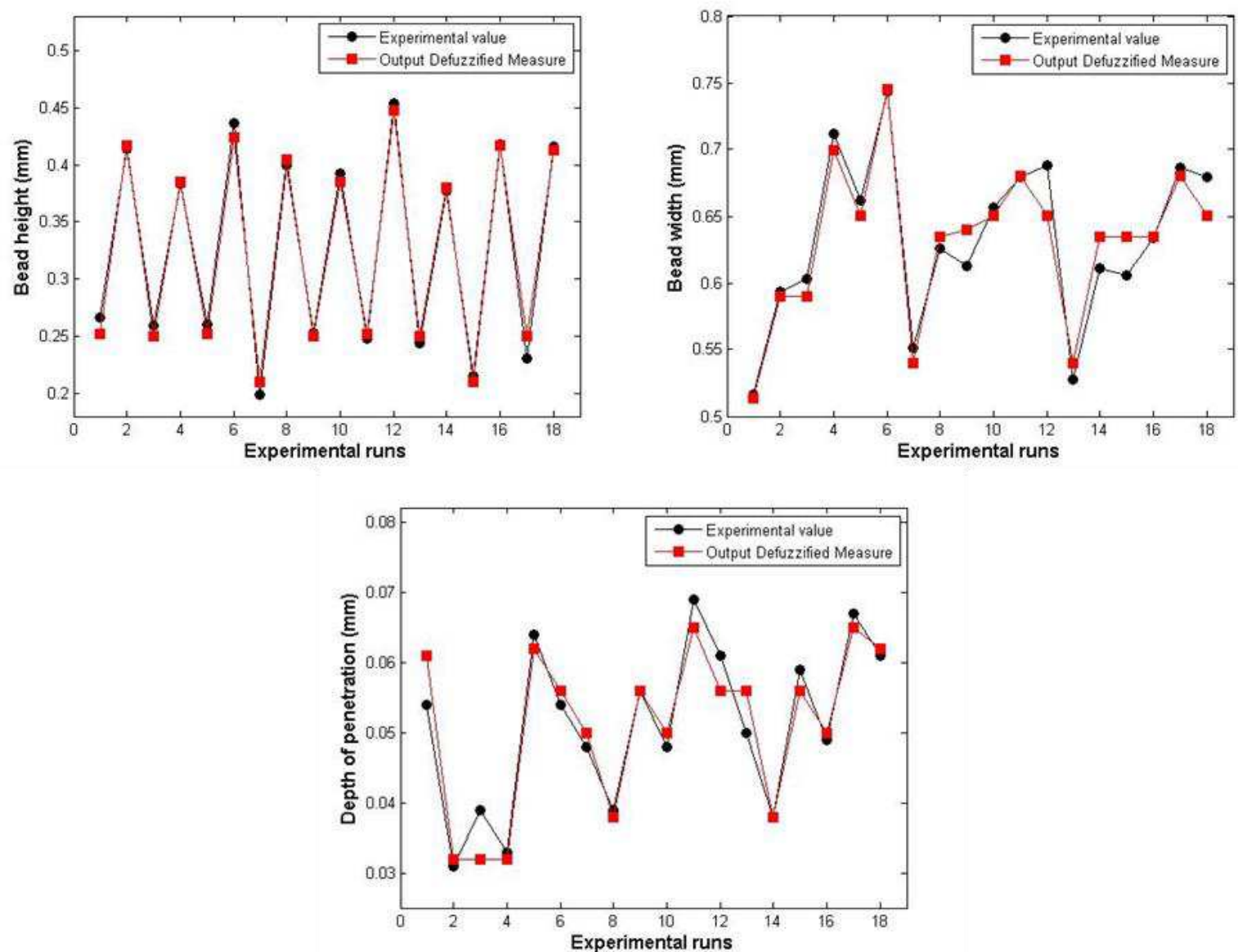

Fig. 15. Correlation between fuzzy predicted values and experiments for bead height $(B h)$, bead width $(B w)$ and depth of penetration $(d p)$.
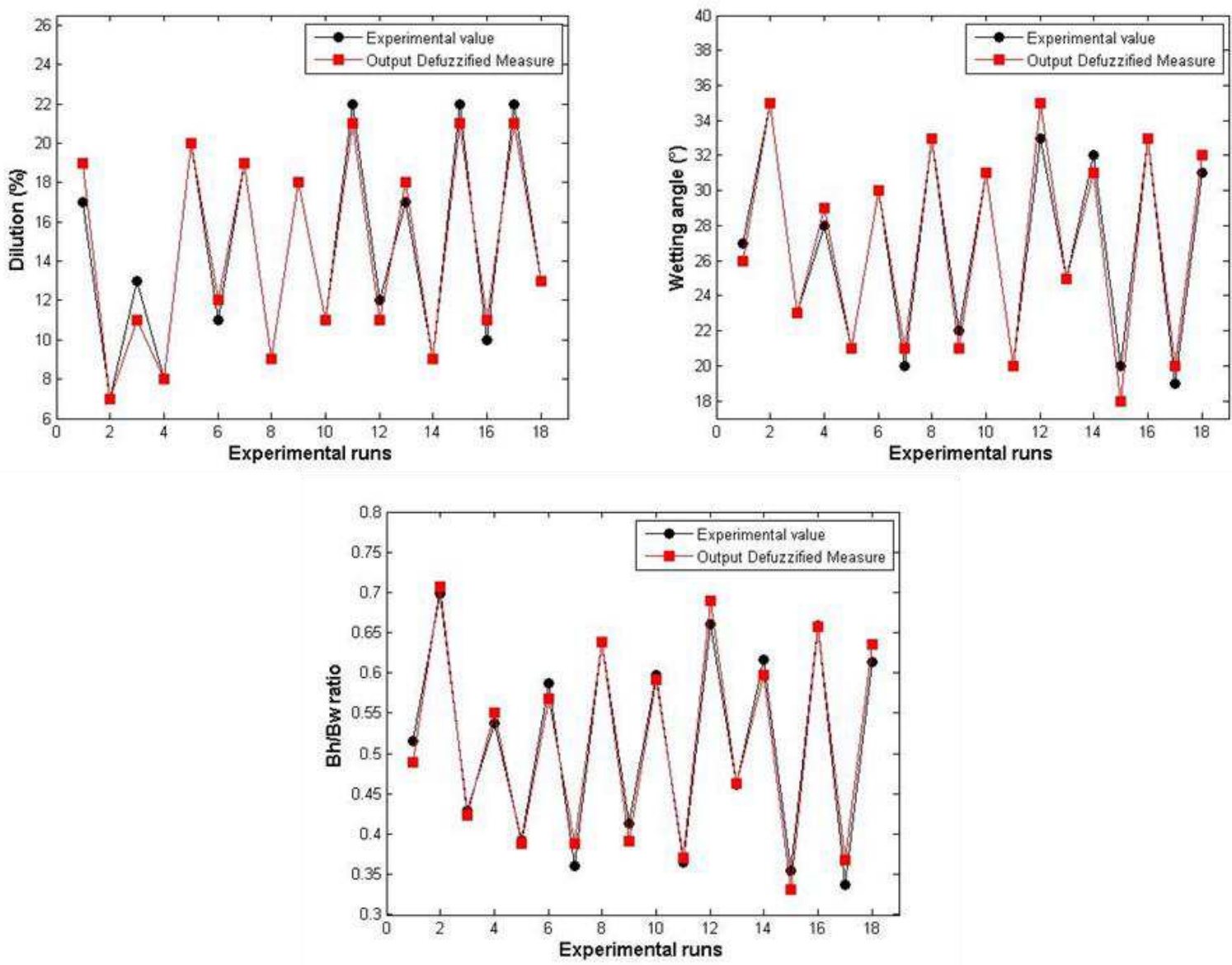

Fig. 16. Correlation between fuzzy predicted values and experiments for (d) dilution (d), wetting angle (wa) and $B h / B w$ ratio. 


\section{Conclusions}

In this paper, a technique of fuzzy inference was used to develop two models for predicting the geometrical characteristics (bead height, bead width and depth of penetration) and for optimizing the LMD process parameters using AISI 316 stainless steel powder and substrate. The main conclusions of the work allow us to affirm that:

- With analysis of variance (ANOVA), it was confirmed that the powder flow parameter had a significant effect on $B h$, $B h / B w$ ratio, $d$ and $w a$; $w$ hile, on $B w$ and $d p$, the laser power had the greatest influence. On $B w$ and $d p$, the laser power had the greatest influence. It was noticed that there is a proportional relationship between height/width index and the wetting angle. The greatest height $(B h)$ was $0.454 \mathrm{~mm}$, and the largest width $(B w)$ was $0.743 \mathrm{~mm}$. The highest depth of penetration $(d p)$ was $0.069 \mathrm{~mm}$.

- The results of the predictive fuzzy model presented a high correlation index when compared with the experimental data. The total error was up to $8.74 \%$ and the average error lower than $3 \%$. The fuzzy system structured to determine the best interaction of process parameters that meets the fuzzy system optimization features indicated that the 0.845 ODI represents a laser power of $250 \mathrm{~W}, 5 \mathrm{~mm}$ of focal length and $9.40 \mathrm{~g} / \mathrm{s}$ of powder flow.

- The developed fuzzy model can be improved and integrated with an automated LMD process environment to reduce the hybrid process planning activities complexity and increase process stability.

- Future research could focus on studying the influence of the variation of these parameters on the same variables studied and on the efficiency of multilayer deposition and with different types of powder. Also, further studies analyzing and simulating the influence of input energy density on hybrid additive-subtractive deposited beads could be developed.

- The results show that the fuzzy inference model based on the Mamdani method provides an accurate prediction of the evaluated output variables and good reliability and stability of the approach.

\section{Ethical Approval}

Not applicable

\section{Consent to Participate}

Not applicable

\section{Consent to Publish}

Not applicable

\section{Authors Contributions}

Daniel René Tasé Velázquez designed and implemented the fuzzy models and analyzed the results. André Luís Helleno designed the experiments, helped verify the results and supervised the project. Hipólito Carvajal Fals performed the tests and collected the data. Raphael Galdino dos Santos helped to perform the tests, collect data and verify the results. All authors discussed the results and contributed to the final manuscript.

\section{Funding and acknowledgement}

The authors would like to thank the Higher Education Personnel Improvement Coordination - Brazil (CAPES Coordenação de Aperfeiçoamento de Pessoal de Nivel Superior) which financed this study in part - Finance Code 001. In addition, the authors would like to thank the ROMI Industry for allowing the open and wide access to their facilities for studying the hybrid system ROMI DCM 620-5X HYBRID.

\section{Availability of data and materials}

The data that support the findings of this work are available on request from the corresponding author.

\section{Conflict of interests}

The authors declare that they have no conflict of interest.

\section{References}

1. Karunakaran K, Suryakumar S, Pushpa V, Akula S (2010) Low cost integration of additive and subtractive processes for hybrid layered manufacturing. Robot. C.-Integ. Manufac. 26:490-499. https://doi.org/10.1016/j.rcim.2010.03.008

2. Newman ST, Zhu Z, Dhokia V, Shokrani A (2015) Process planning for additive and subtractive manufacturing technologies. CIRP Annals - Manuf. Technol. 64:467-470. https://doi.org/10.1016/j.cirp.2015.04.109

3. Flynn J, Shokrani A, Newman ST, Dhokia V (2016) Hybrid additive and subtractive machine tools - Research and industrial developments. Int. J. Mach. Tool Manuf. 101:79-101. https://doi.org/10.1016/j.ijmachtools.2015.11.007 
4. Cortina M, Arrizubieta JI, Ruíz J, Ukar E, Lamikiz A (2018). Latest developments in industrial hybrid machine tools that combine additive and subtractive operations. Mater. 11:1-27. https://doi.org/10.3390/ma11122583

5. Herzog D, Seyda V, Wycisk E, Emmelmann C (2016) Additive manufacturing of metals. Acta Mater. 117. https://doi.org/10.1016/j.actamat.2016.07.019

6. Liverani E, Toschi S, Ceschini L, Fortunato A (2017) Effect of selective laser melting (SLM) process parameters on microstructure and mechanical properties of 316L austenitic stainless steel. J. Mater. Process. Technol. 249:255-263. https://doi.org/10.1016/j.jmatprotec.2017.05.042

7. Shipley H, McDonnell D, Culleton M, Coull R, Lupoi R, O'Donnell G, Trimble D (2018) Optimisation of process parameters to address fundamental challenges during selective laser melting of Ti-6Al-4V: A review. Int. J. Mach. Tool Manuf. 128:1-20. https://doi.org/10.1016/j.ijmachtools.2018.01.003

8. Gu D, Xia M, Dai D (2019) On the role of powder flow behavior in fluid thermodynamics and laser processability of Ni-based composites by selective laser melting. Int. J. Mach. Tool Manuf. 137:67-78. https://doi.org/10.1016/j.ijmachtools.2018.10.006

9. Murkute P, Pasebani S, Isgor OB (2019) Production of corrosion-resistant 316L stainless steel clads on carbon steel using powder bed fusion-selective laser melting. J. Mater. Process. Technol. 273:116243. https://doi.org/10.1016/j.jmatprotec.2019.05.024

10. Morgan D, Agba E, Hill C (2017) Support structure development and initial results for metal Powder Bed Fusion additive manufacturing. Procedia Manuf. 10:819-830. https://doi.org/10.1016/j.promfg.2017.07.083

11. Dutta B, Palaniswamy S, Choi J, Song Lj, Mazumder J (2011) Additive manufacturing by direct metal deposition. Adv. Mater. Process. 169:33-36.

12. Schmidt M, Merklein M, Bourell D, Dimitrov D, Hausotte T, Wegener K, Overmeyer L, Vollertsen F, Levy GN (2017) Laser based additive manufacturing in industry and academia. CIRP Annals - Manuf. Technol. 66:561-583. https://doi.org/10.1016/j.cirp.2017.05.011

13. Lee H-K (2008) Effects of the cladding parameters on the deposition efficiency in pulsed Nd:YAG laser cladding. J Mater. Process. Technol. 202:321-327. https://doi.org/10.1016/j.jmatprotec.2007.09.024

14. Sun Y, Hao M (2012) Statistical analysis and optimization of process parameters in Ti6Al4V laser cladding using Nd: YAG laser. Opt Lasers Eng. 50:985-995. https://doi.org/10.1016/j.optlaseng.2012.01.018

15. Graf B, Ammer S, Gumenyuk A, Rethmeier M (2013) Design of experiments for laser metal deposition in maintenance, repair and overhaul applications. Procedia CIRP 11:245-248. https://doi.org/10.1016/j.procir.2013.07.031

16. Farahmand P, Kovacevic R (2014) Parametric study and multicriteria optimization in laser cladding by a high power direct diode laser. Lasers Manuf. Mater. Process. 1:1-20. https://doi.org/10.1007/s40516-014-0001-0

17. Liu S, Kovacevic R (2014) Statistical analysis and optimization of processing parameters in high-power direct diode laser cladding. Int J Adv Manuf Technol. 74:867-878. https://doi.org/10.1007/s00170-014-6041-y

18. Yu T, Zhao Y, Sun J, Chen Y, Qu W (2018) Process parameters optimization and mechanical properties of forming parts by direct laser fabrication of YCF101 alloy. J. Mater. Process. Technol. 262:75-84. https://doi.org/10.1016/j.jmatprotec.2018.06.023

19. Wu J, Liu T, Chen H, Lia F, Wei H, Zhang Y (2019) Simulation of laser attenuation and heat transport during direct metal deposition considering beam profile. J. Mater. Process. Technol. 270:92-105. https://doi.org/10.1016/j.jmatprotec.2019.02.021

20. Huang Y, Ansari M, Asgari H, Hossein M, Farshidianfar MH, Sarker D, Khamesee MB, Toyserkani E (2019) Rapid prediction of real-time thermal characteristics, solidification parameters and microstructure in laser directed energy deposition (powder-fed additive manufacturing). J. Mater. Process. Technol. 274:116286. https://doi.org/10.1016/j.jmatprotec.2019.116286

21. Ansari M, Mohamadizadeh A, Huang Y, Paserin V, Toyserkani E (2019) Laser directed energy deposition of water-atomized iron powder: Process optimization and microstructure of single-tracks. Opt. L. Technol. 112:485-493. https://doi.org/10.1016/i.optlastec.2018.11.054

22. Nagesh DS, Datta GL (2002) Prediction of weld bead geometry and penetration in shielded metal-arc welding using artificial neural networks. J. Mater. Process. Technol. 123:303-312. https://doi.org/10.1016/S0924-0136(02)00101-2

23. Supriadi S, Manabe K (2013) Enhancement of dimensional accuracy of dieless tube-drawing process with vision-based fuzzy control. J. Mater. Process. Technol. 213:905-912. https://doi.org/10.1016/j.jmatprotec.2012.12.011

24. Lin JL, Lin CL (2005) The use of grey-fuzzy logic for the optimization of the manufacturing process. J. Mater. Process. Technol. 160:9-14. https://doi.org/10.1016/j.jmatprotec.2003.11.040

25. Wu BH, Wang J-JJ (2009) A neuro-fuzzy approach to generating mold/die polishing sequences. J. Mater. Process. Technol. 209:3241-3250. https://doi.org/10.1016/j.jmatprotec.2008.07.031

26. Tan H, Tarasov V, Jarfors AEW, Seifeddine S (2021) A design of fuzzy inference systems to predict tensile properties of as-cast alloy. Int J Adv Manuf Technol. https://doi.org/10.1007/s00170-020-06502-4

27. Genna S, Lambiase F, Ponticelli GS (2020) Fuzzy decision-making in laser-assisted joining of polymer-metal hybrid structures. Int J Adv Manuf Technol 108:61-72. https://doi.org/10.1007/s00170-020-05379-7

28. Indústrias ROMI. ROMI DCM 620-5X HYBRID Technical specifications. Available in: https://www.romi.com/wpcontent/uploads/2017/10/fol_romi_dcm_hybrid_po_aa_052017_baixa.pdf. Access February 2019.

29. Alam M, Urbanic R, Nazemi N, Edrisy A (2018) Predictive modeling and the effect of process parameters on the hardness and bead characteristics for laser-cladded stainless steel. Int. J. Adv. Manuf. Technol. 94:397-413. https://doi.org/10.1007/s00170-017-0898$\underline{5}$

30. Rao PS, Gupta OP, Murty SSN, Rao ABK (2009) Effect of process parameters and mathematical model for the prediction of bead geometry in pulsed GMA welding. Int J Adv Manuf Technol. 45:496-505. https://doi.org/10.1007/s00170-009-1991-1 
31. Caiazzo F (2018) Laser-aided Directed Metal Deposition of Ni-based superalloy powder. Opt. L. Technol. 103:193-198. https://doi.org/10.1016/i.optlastec.2018.01.042

32. Calleja A, Tabernero I, Fernández A, Celaya A, Lamikiz A, López de Lacalle LN (2014) Improvement of strategies and parameters for multi-axis laser cladding operations. Opt. L. Eng. 56:113-120. https://doi.org/10.1016/j.optlaseng.2013.12.017

33. Latha B, Senthilkumar VS (2010) Modeling and analysis of surface roughness parameters in drilling GFRP composites using fuzzy logic. Mater. Manuf. Proces. 25:817-827. https://doi.org/10.1080/10426910903447261

34. Gomide FC, Gudwin R, Tanscheit R (1995) Conceitos fundamentais da teoria de conjuntos fuzzy, lógica fuzzy e aplicações. In: Proc. 6th IFSA Congress-Tutorials, pp. 1-38.

35. Zadeh LA (1965) Fuzzy Sets. Inf Control 8:338-353. https://doi.org/10.1016/S0019-9958(65)90241-X

36. Mamdani E, Assilian S (1975) An experiment in linguistic synthesis with a fuzzy logic controller. Int. J. Man Mach. Stud. 7:1-13. https://doi.org/10.1016/S0020-7373(75)80002-2

37. Saade JJ, Diab HB (2004) Defuzzification methods and new techniques for fuzzy controllers. I. J. Elect. Comp. Eng. 3:161-174. Available in: https://pdfs.semanticscholar.org/8781/b6f848e356eff46f3160efb3d0b5d50d077c.pdf. Access March 2019.

38. Zimmermann H-J (2001). Fuzzy set theory and its applications. 4th ed. Springer Science + Business Media New York.

39. Das B, Roy S, Rai RN, Saha SC (2016) Application of grey fuzzy logic for the optimization of CNC milling parameters for Al4.5\% Cu-TiC MMCs with multi-performance characteristics. Eng. Sci. Technol. I. J. 19:857-865. 


\section{Figures}
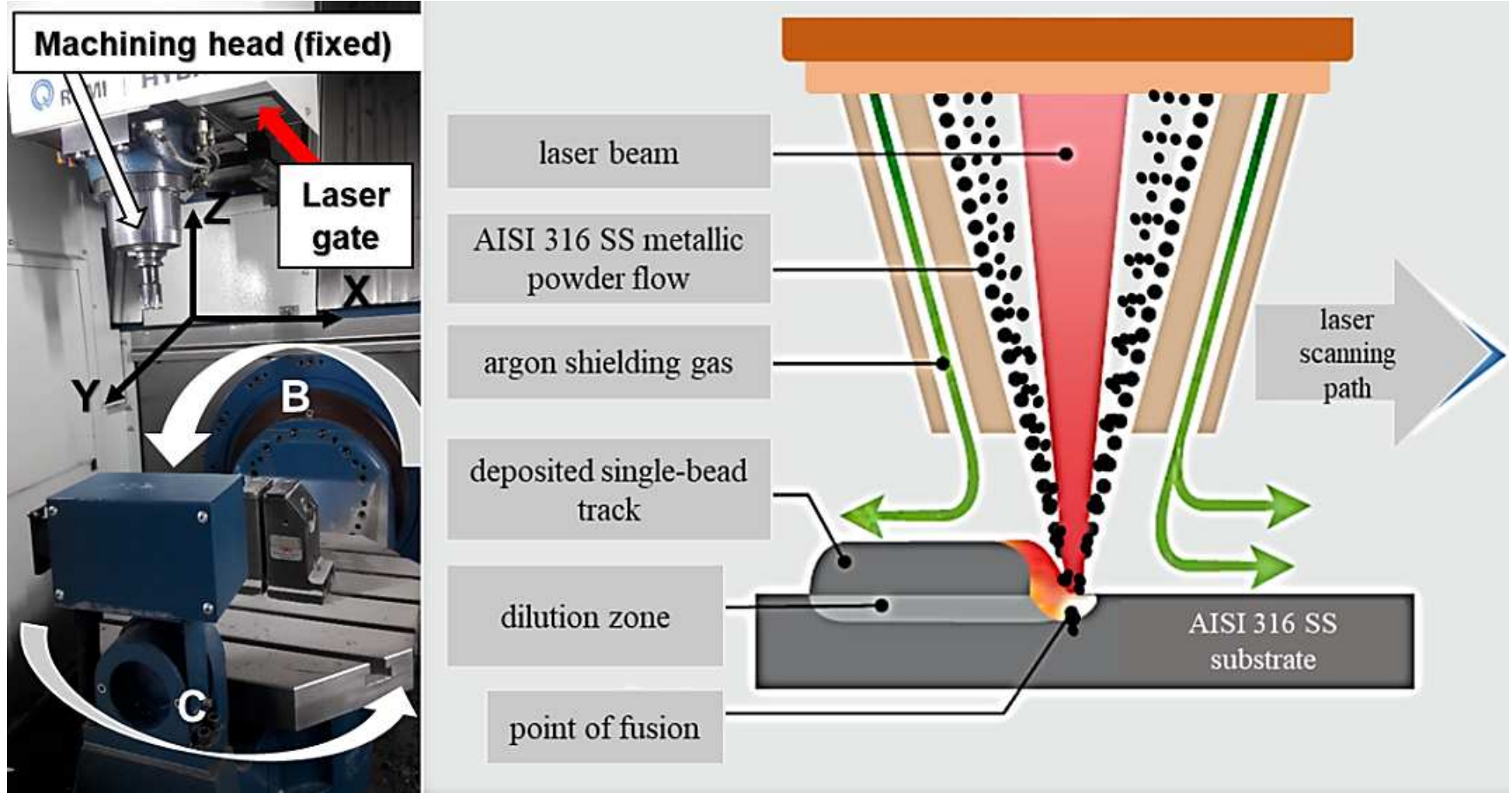

Figure 1

Hybrid system configuration, operational axes, and laser operational principle. Adapted from ROMI [28].
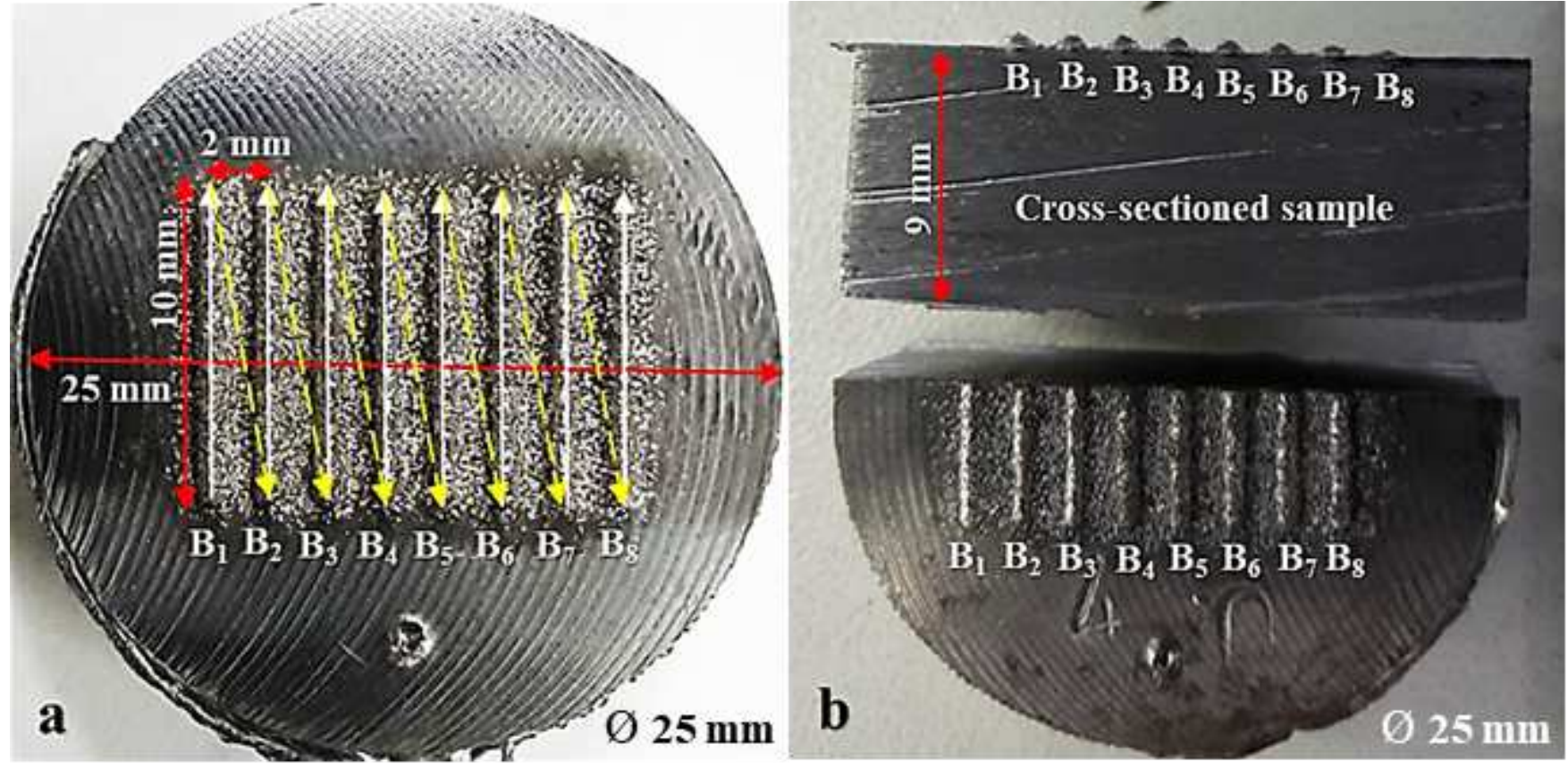

Figure 2

(a) Sample dimensions, (b) cross section. 


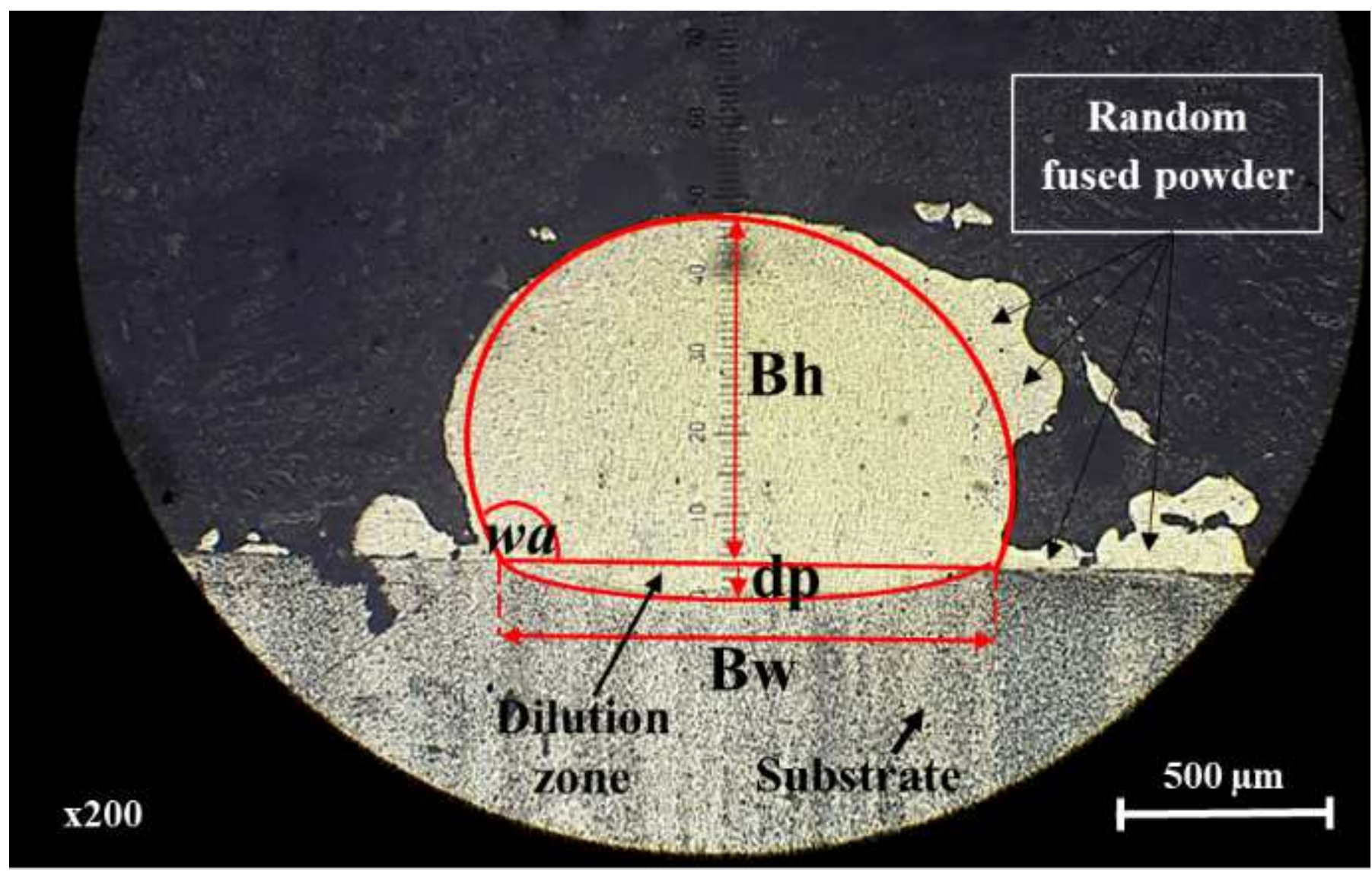

\section{Figure 3}

Bead sample cross-section showing the bead height (Bh), bead width (Bw), depth of penetration (dp), wetting angle (wa) and dilution zone.

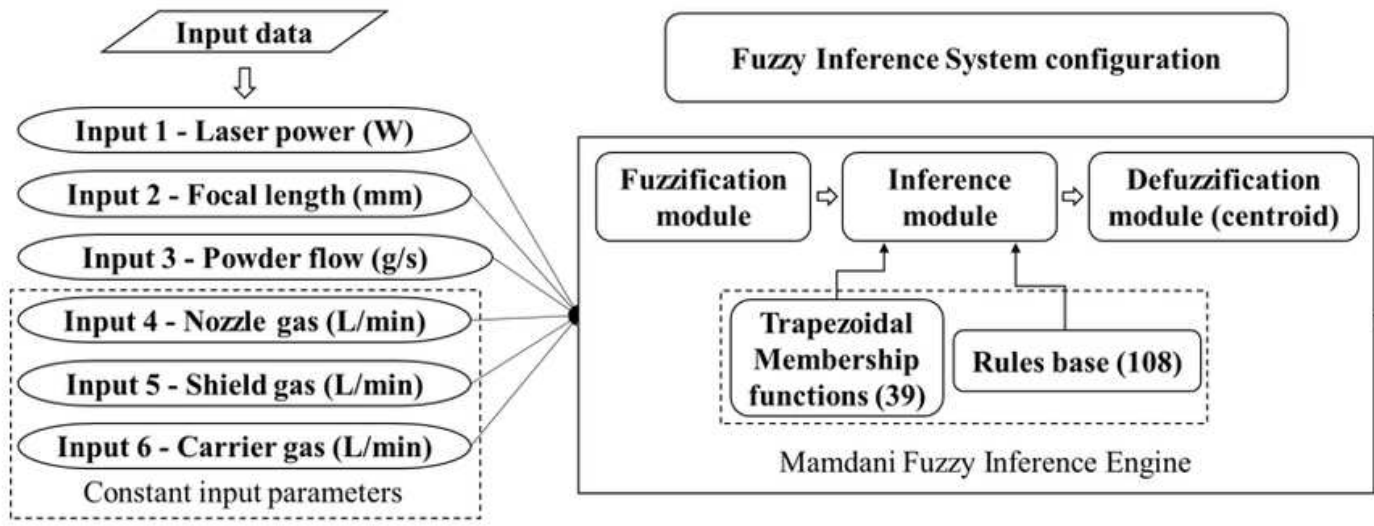

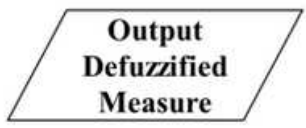

$\sqrt{3}$

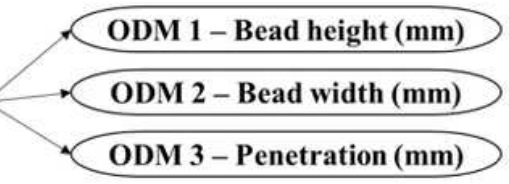

\section{Figure 4}

FIS configuration for bead height, bead width and depth of penetration prediction. 

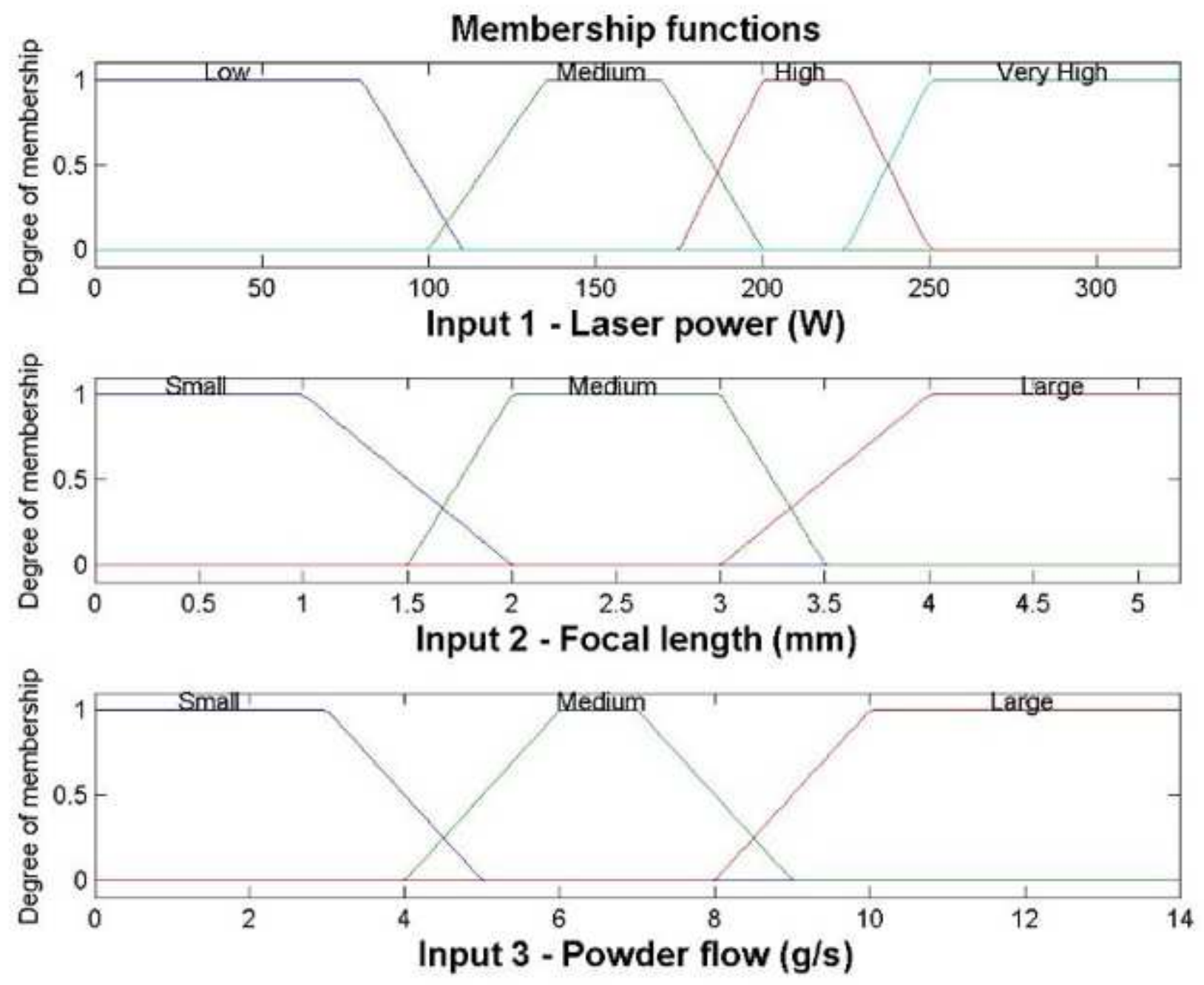

Figure 5

Membership functions and fuzzy sets for input process parameters. 

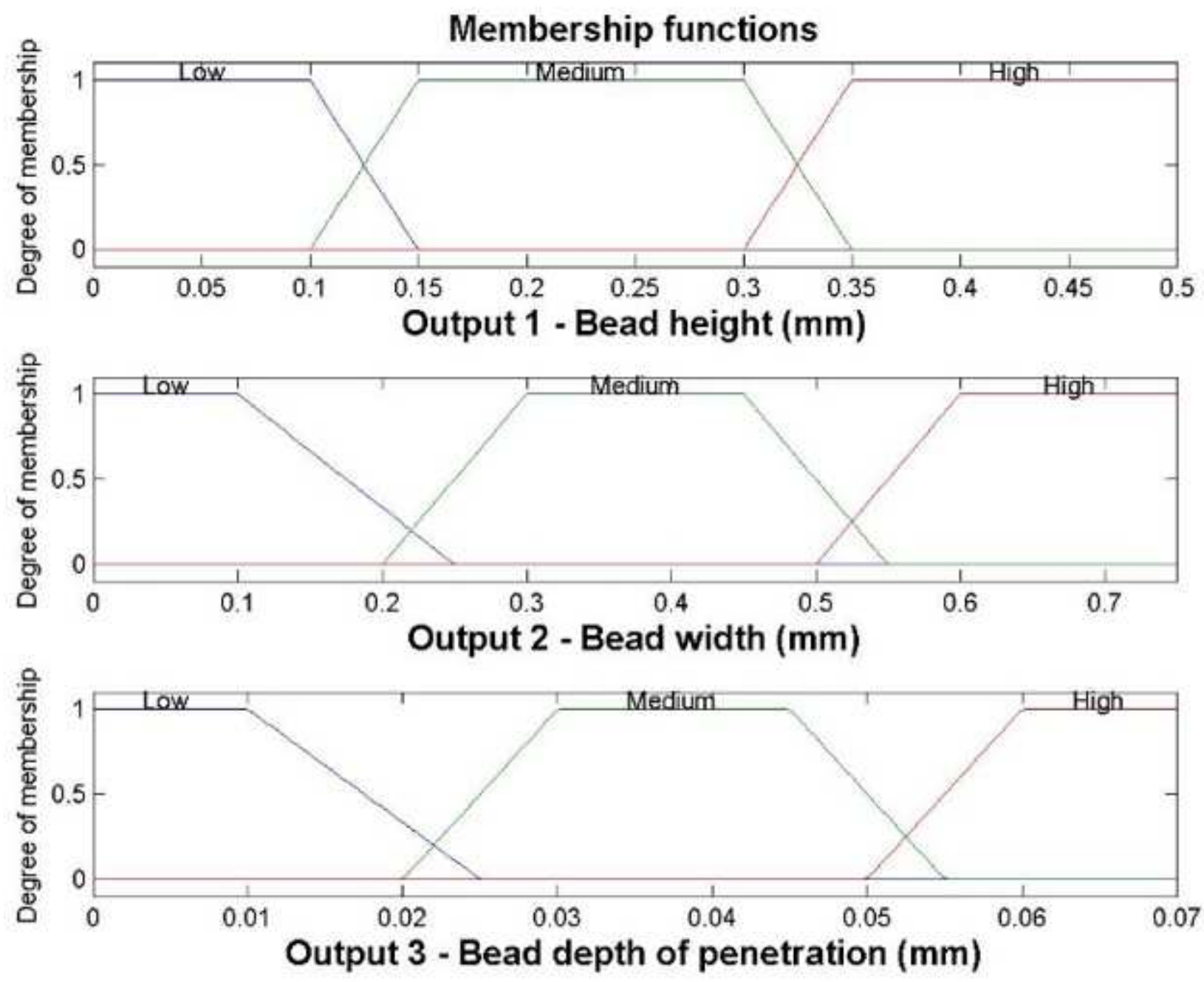

Figure 6

Membership functions and fuzzy sets for estimated outputs.

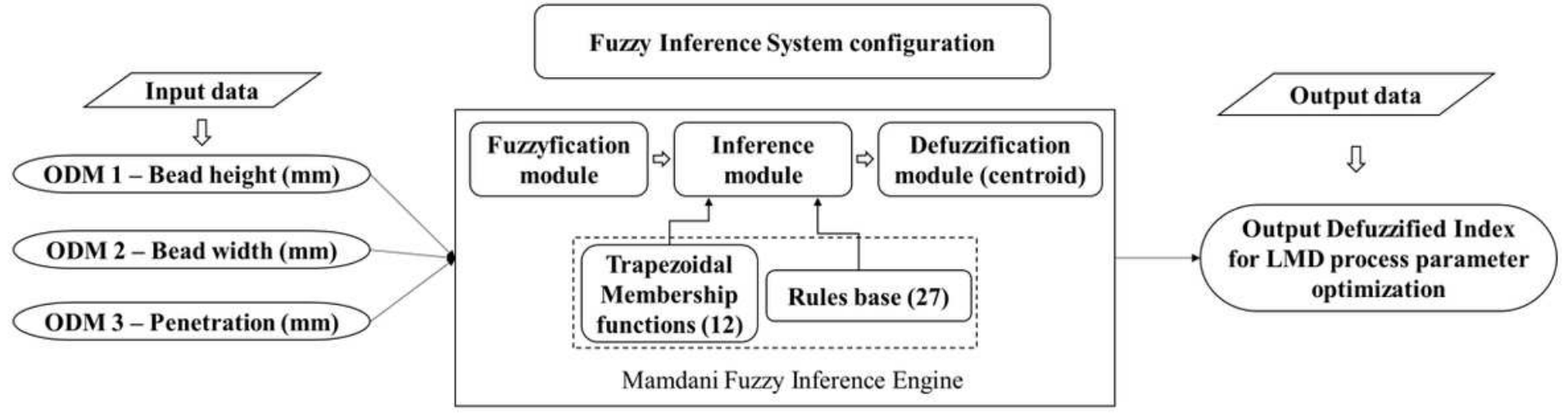

Figure 7

FIS configuration for LMD process parameter optimization. 


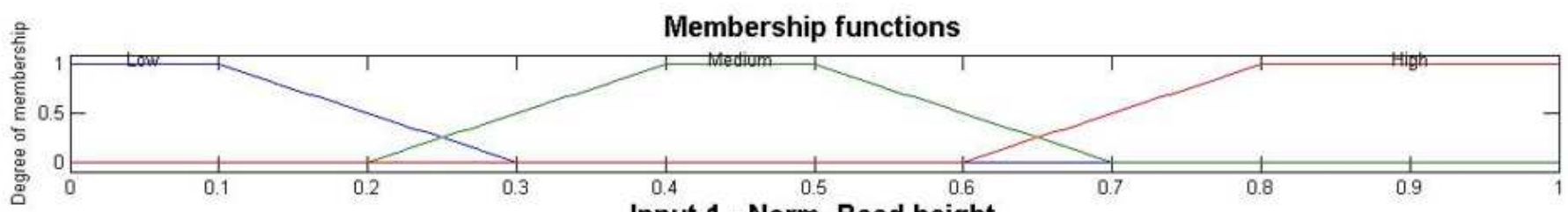

Input 1 - Norm. Bead height

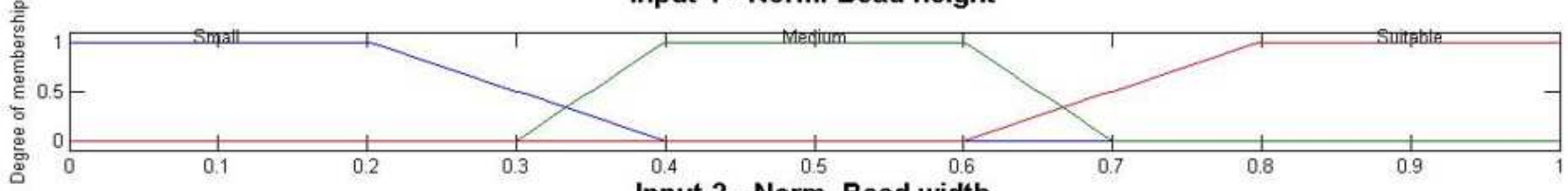

Input 2 - Norm. Bead width

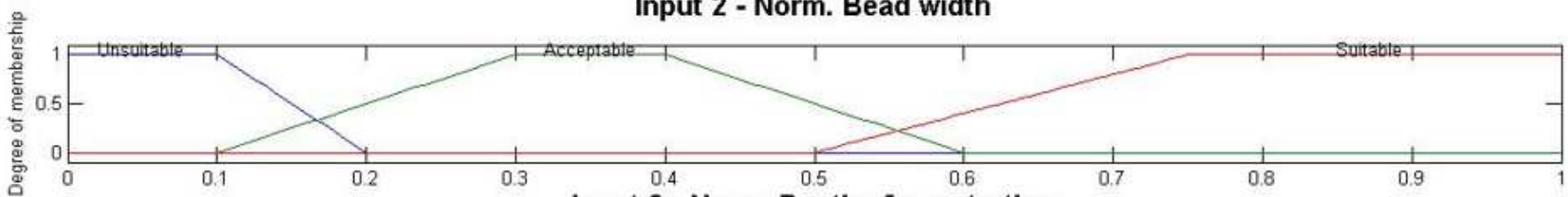

Input 3 - Norm. Depth of penetration

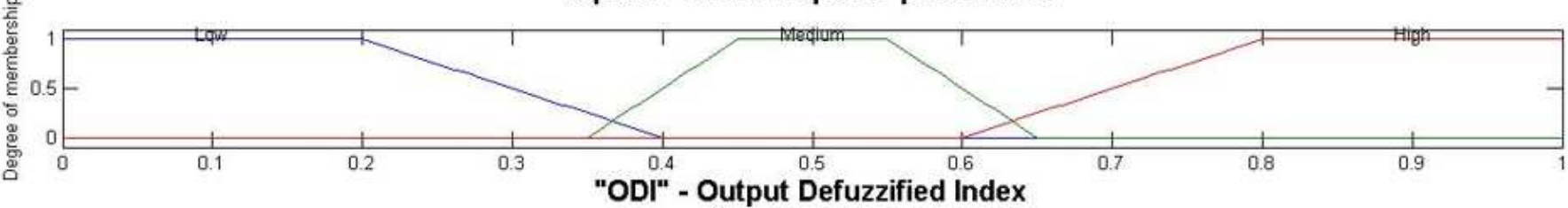

Figure 8

Membership functions and fuzzy sets for Membership functions and fuzzy sets for input normalized parameters bead height, bead width and depth of penetration, and estimated output index. 


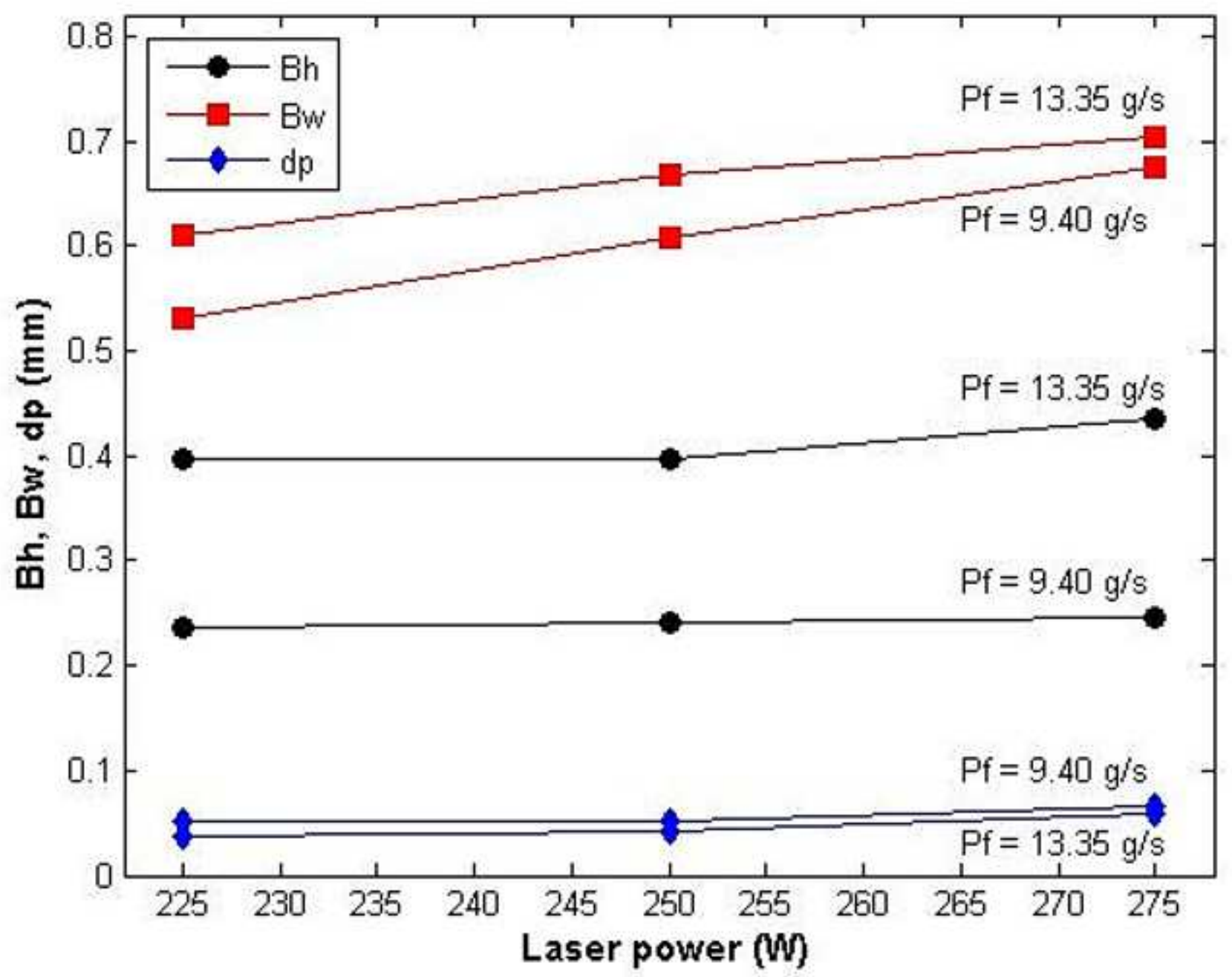

Figure 9

(a) Mean values of $B h, B w$ and dp for $L p(W)$ and $P f(g / s)$ interaction. 

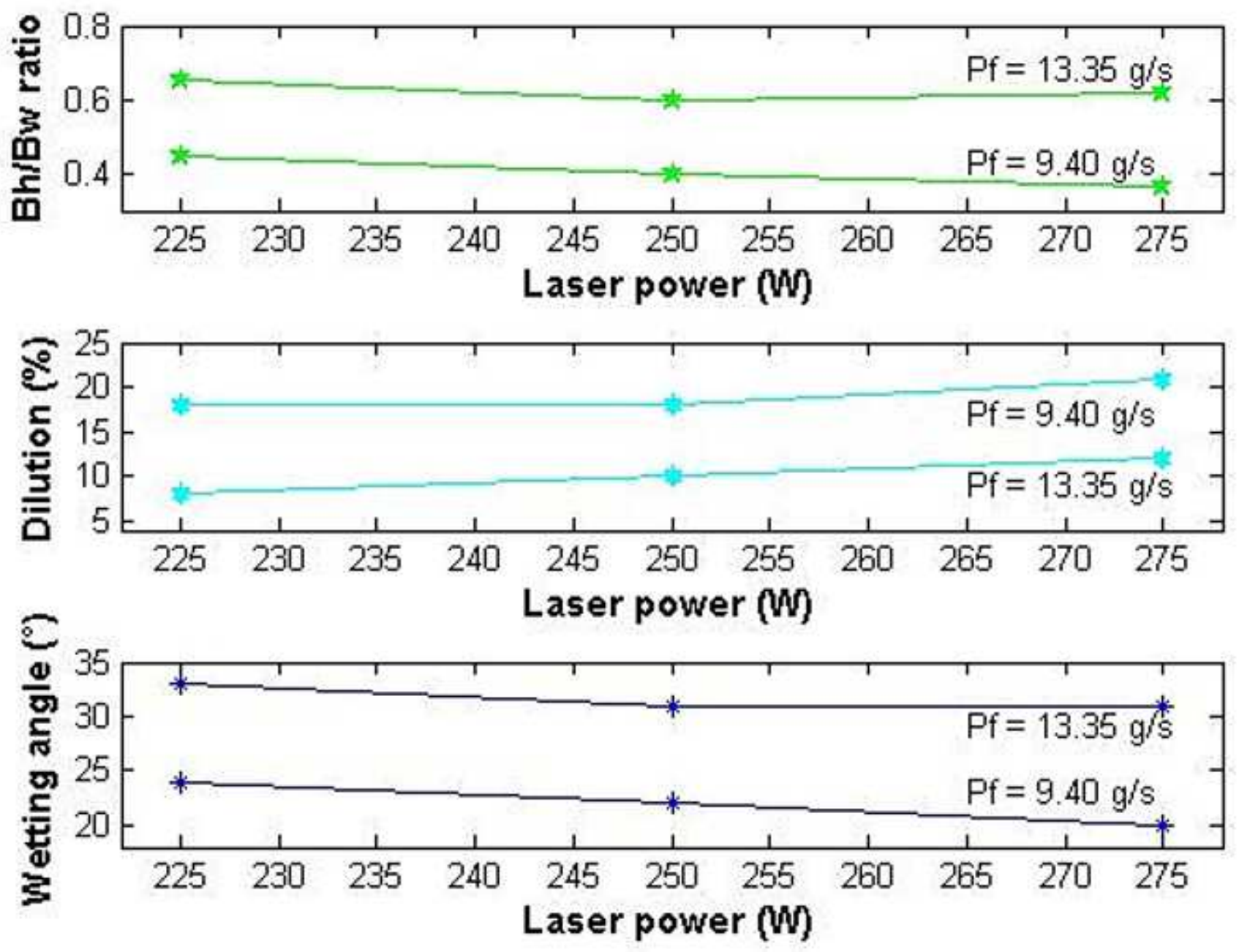

Figure 10

Mean values of Bh/Bw ratio, dilution (d) and wetting angle (wa) for $\mathrm{Lp}(\mathrm{W})$ and $\mathrm{Pf}(\mathrm{g} / \mathrm{s})$ interaction.

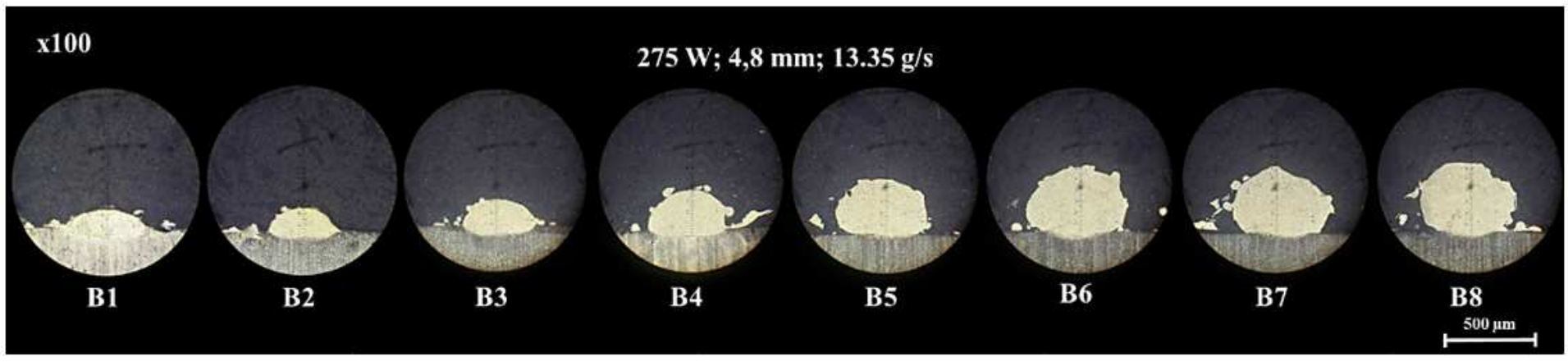

Figure 11

Cross section of eight strands generated in the LMD process. 


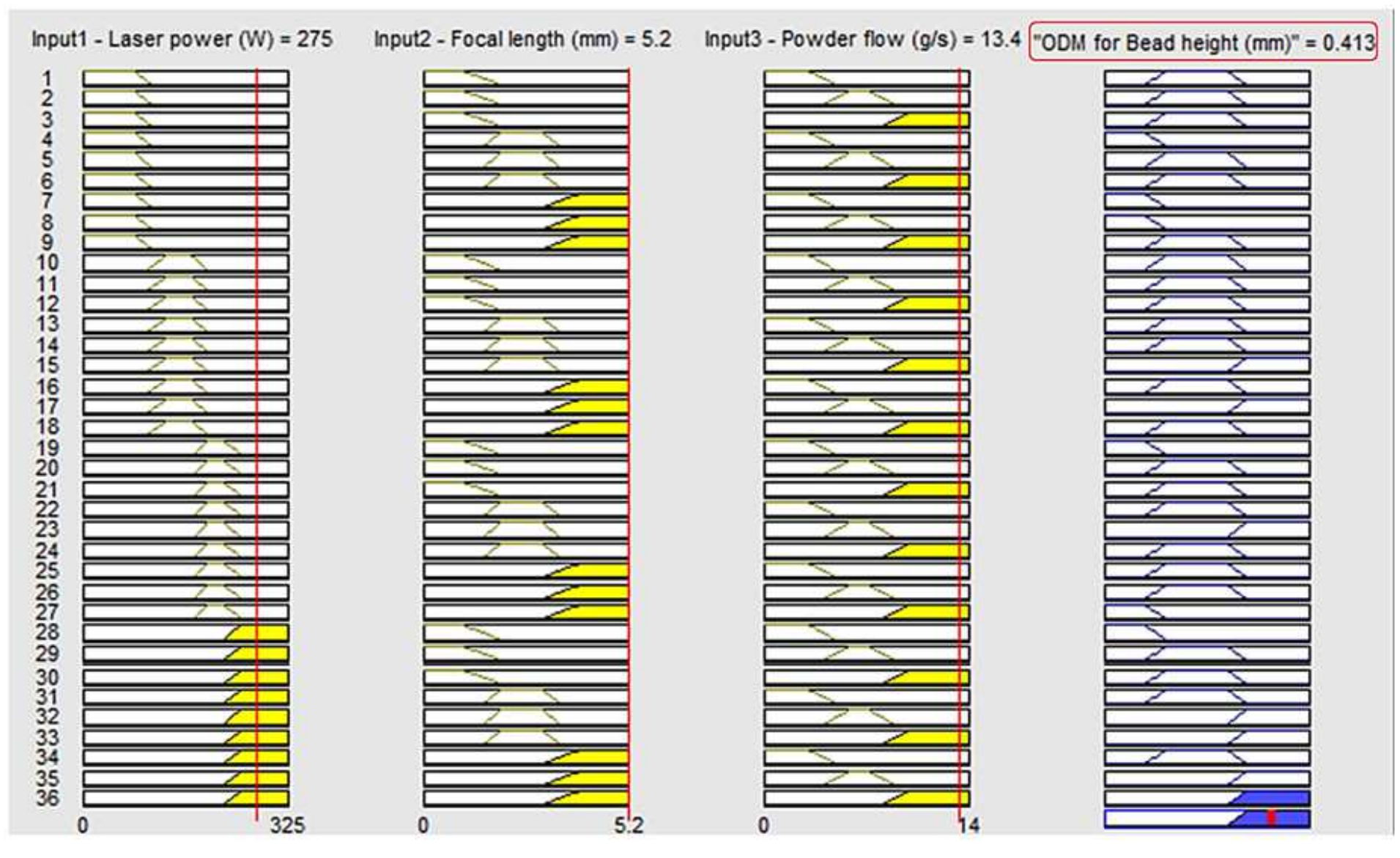

Figure 12

Rules viewer and ODM of predicted bead height. 
(a)
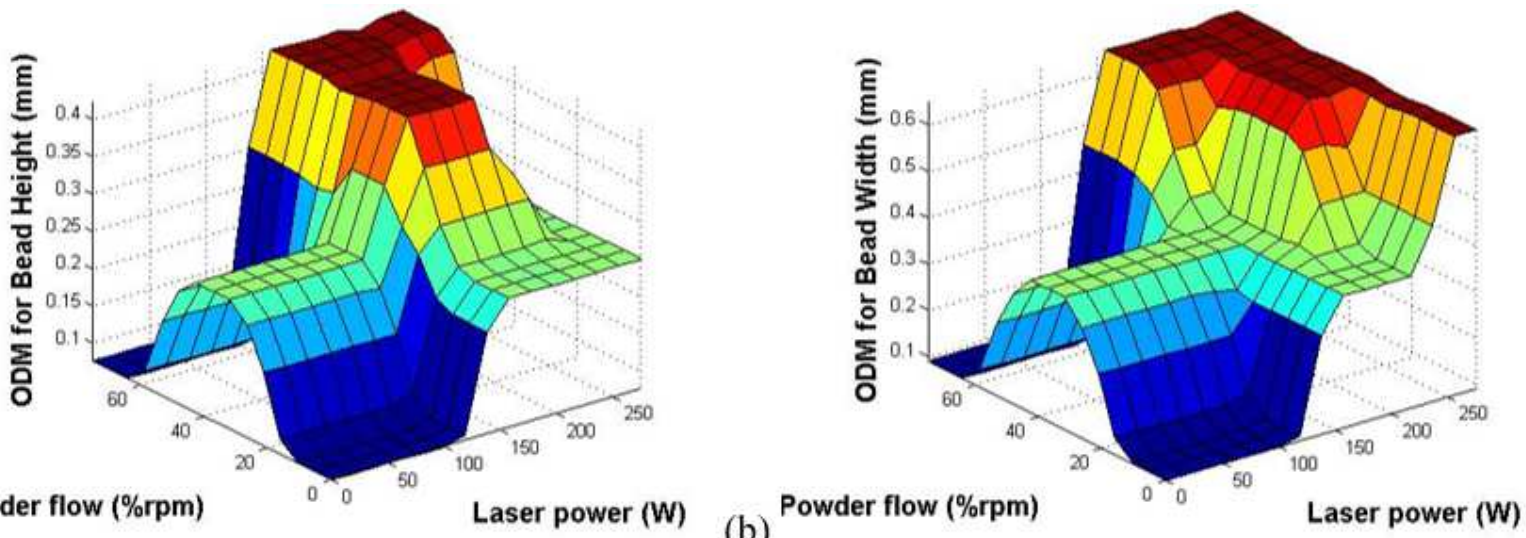

(c)

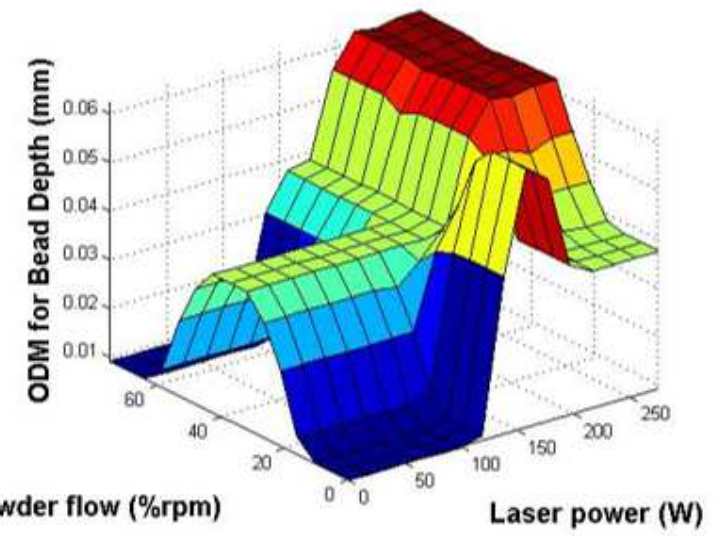

\section{Figure 13}

ODM 3D maps for (a) predicted Bh, (b) for predicted Bw, (c) for predicted dp.

\begin{tabular}{|c|c|c|c|c|}
\hline \multicolumn{2}{|r|}{ Input1 - Bead height index $=0.149$} & Input2 - Bead width index $=0.282$ & Input3 - Depth of penetration index $=0.211$ & "ODI for optimum parameter ranges" $=0.171$ \\
\hline 1 & \% & ${ }_{-1}$ & $\square$ & 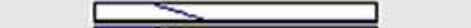 \\
\hline 2 & $\mathrm{~B}^{2}$ & $=$ & 車 & בר \\
\hline 3 & EN & $=$ & 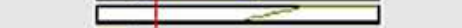 & $\bar{s}$ \\
\hline 4 & $E^{2}$ & 2 & $\square$ & Sis \\
\hline 5 & Ex & 2 & 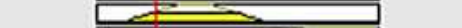 & 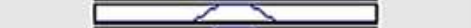 \\
\hline 6 & $\mathrm{~B}^{2}$ & 1 & 1 & $\overline{5}$ \\
\hline 7 & E> & 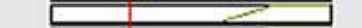 & 5 & $\infty$ \\
\hline 8 & ${ }^{2}=$ & $\infty$ & 2 & 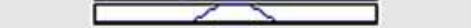 \\
\hline 9 & $E$ & 2 & $=$ & $\Sigma$ \\
\hline 10 & W & Ex & 5 & $\pi$ \\
\hline 11 & +2 & $=2$ & בר & $\overline{5}$ \\
\hline 12 & 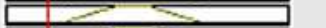 & $\overline{2}$ & 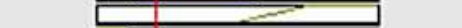 & $\bar{\Sigma}$ \\
\hline 13 & \begin{tabular}{|l|l|} 
& \multicolumn{2}{c}{$=0$} \\
\end{tabular} & 3 & 5 & 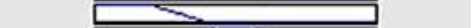 \\
\hline 14 & 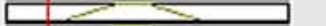 & 3 & 2 & 5 \\
\hline 15 & \begin{tabular}{l|l} 
& $<$ \\
\end{tabular} & $2 \geq$ & $\approx$ & 2 \\
\hline 16 & 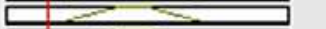 & $=$ & 5 & $\bar{S}$ \\
\hline 17 & $=0$ & $=$ & L年 & 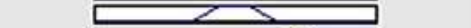 \\
\hline 18 & 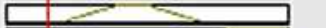 & 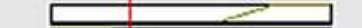 & 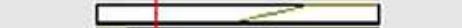 & 2 \\
\hline 19 & 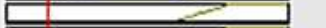 & ${ }_{\infty}$ & 2 & $\mathrm{~N}$ \\
\hline 20 & \begin{tabular}{|l|l|} 
& \\
\end{tabular} & $\sum$ & 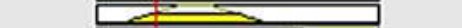 & 5 \\
\hline 21 & \begin{tabular}{|l|l|} 
& \\
\end{tabular} & $\sum$ & $=$ & 2 \\
\hline 22 & 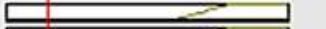 & $\sum$ & 5 & $\overline{\mathrm{S}}$ \\
\hline 23 & 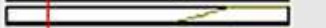 & $\sum$ & 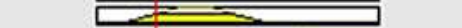 & 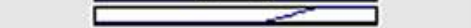 \\
\hline 24 & \begin{tabular}{|l|l|} 
& \\
\end{tabular} & $z$ & 2 & 2 \\
\hline 25 & \begin{tabular}{|l|l} 
& \\
\end{tabular} & $=$ & $\square$ & 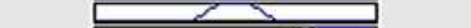 \\
\hline 26 & \begin{tabular}{|l|l} 
& \\
\end{tabular} & $\leq$ & 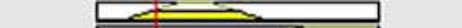 & $\approx$ \\
\hline 27 & \begin{tabular}{l|l} 
& \\
\end{tabular} & 0 & 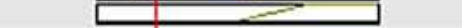 & $z$ \\
\hline
\end{tabular}

Figure 14

Rules viewer and ODI for optimum process parameter ranges. 

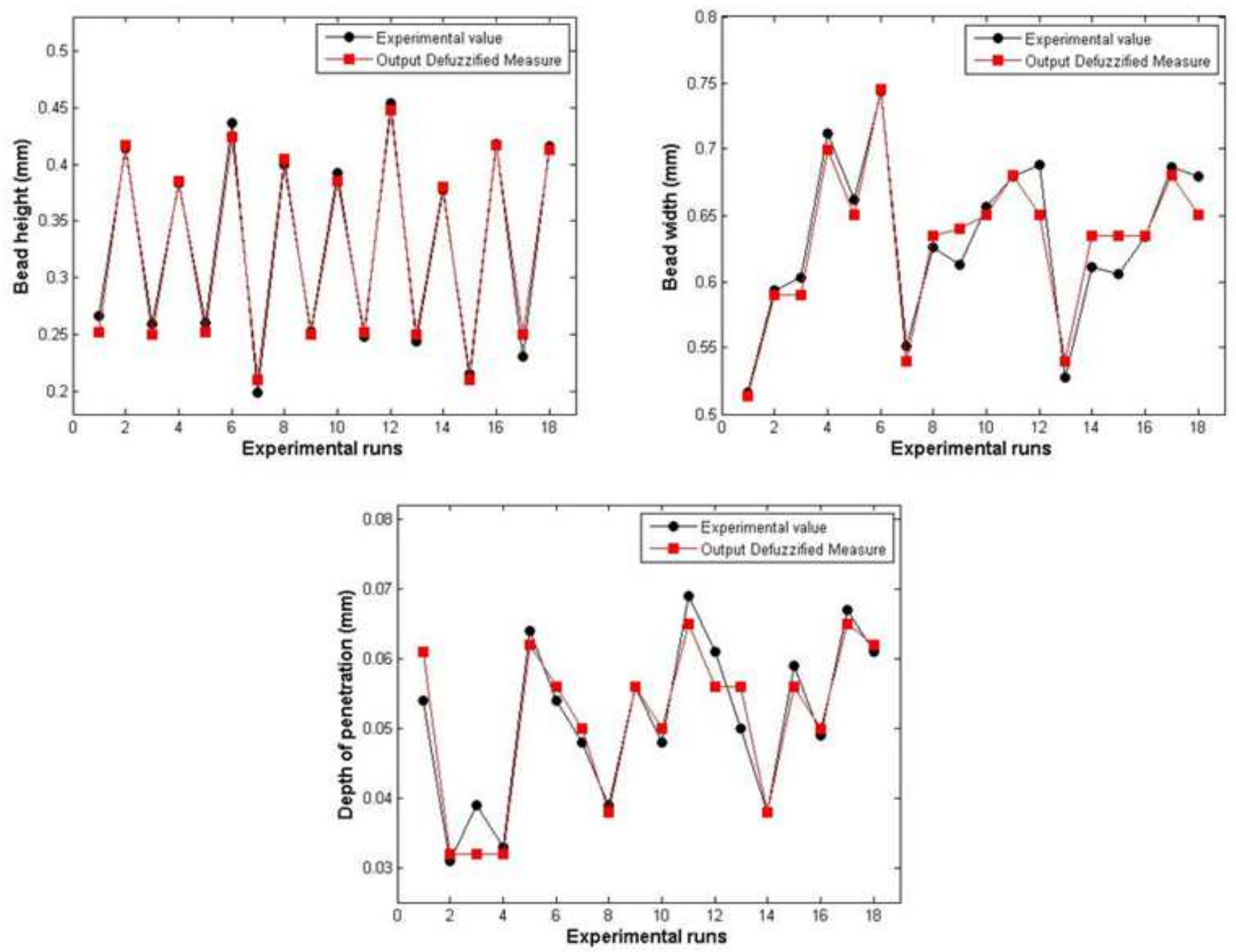

Figure 15

Correlation between fuzzy predicted values and experiments for bead height (Bh), bead width (Bw) and depth of penetration (dp). 

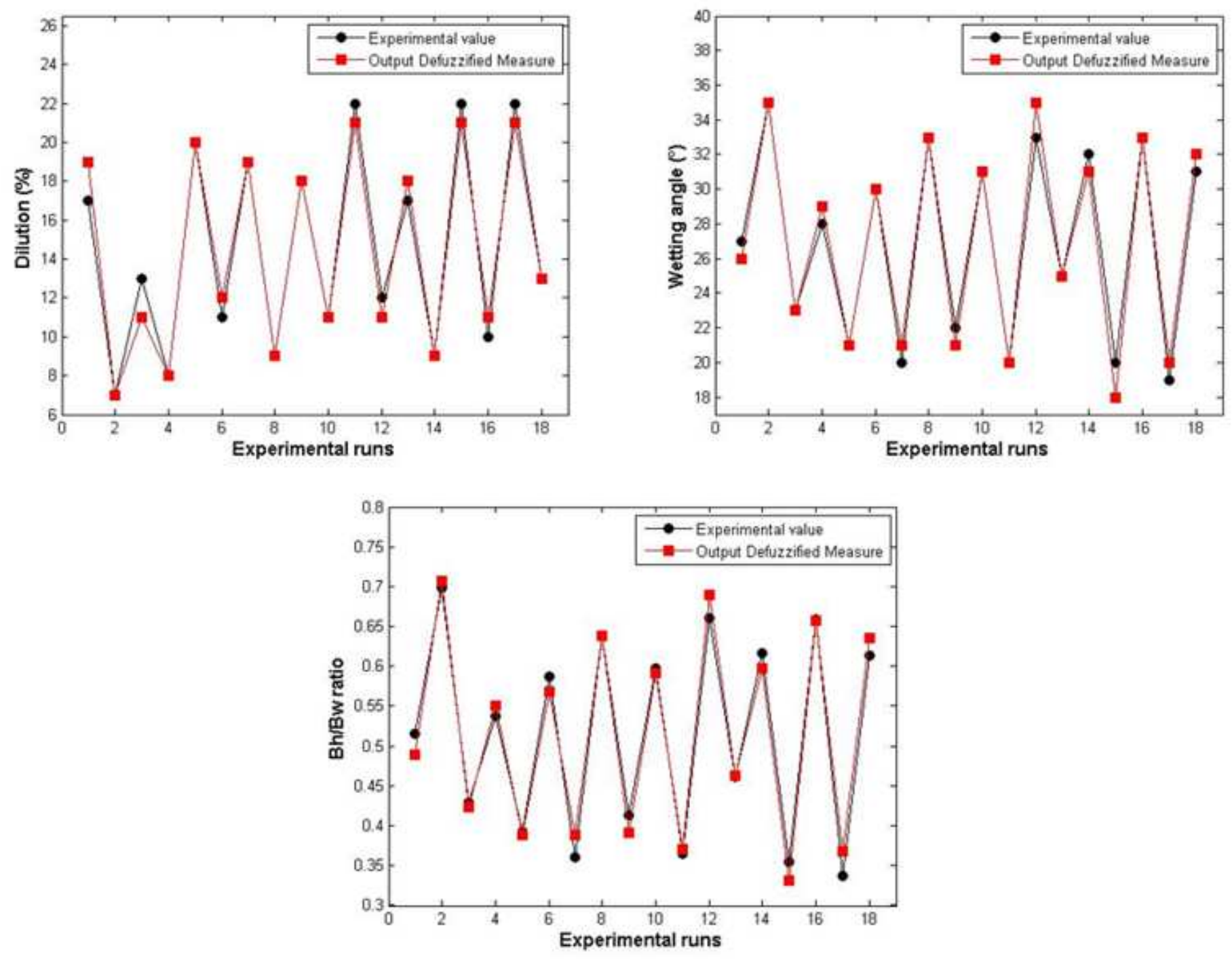

Figure 16

Correlation between fuzzy predicted values and experiments for (d) dilution (d), wetting angle (wa) and $\mathrm{Bh} / \mathrm{Bw}$ ratio. 